\title{
In situ Tribo-Fluorination for Oil-Less Hermetic Compressor Applications
}

\author{
Gabriel Borges ${ }^{1}$, Diego Salvaro ${ }^{1}$, Roberto Binder ${ }^{2}$, Cristiano Binder ${ }^{1}$, Aloisio N. Klein ${ }^{1}$ and \\ Jose D. B. de Mello ${ }^{1,2,3 *}$ \\ ${ }^{1}$ Laboratório de Materiais, Departamento de Engenharia Mecânica, Universidade Federal de Santa Catarina, Florianópolis, \\ Brazil, ${ }^{2}$ Nidec Global Appliance - Unidade Embraco, Joinville, Brazil, ${ }^{3}$ Laboratório de Tribologia e Materiais, Departamento de \\ Engenharia Mecânica, Universidade Federal de Uberlândia, Uberlândia, Brazil
}

\section{OPEN ACCESS}

Edited by:

Enrico Ciulli,

University of Pisa, Italy

Reviewed by:

Noritsugu Umehara,

Nagoya University, Japan

Erik Kuhn,

Hamburg University of Applied Sciences, Germany

*Correspondence: Jose D. B. de Mello

Itm-demello@ufu.br

Specialty section:

This article was submitted to

Tribology,

a section of the journal

Frontiers in Mechanical Engineering

Received: 11 January 2021

Accepted: 23 February 2021

Published: 17 March 2021

Citation:

Borges G, Salvaro D, Binder $R$, Binder C, Klein AN and de Mello JDB

(2021) In situ Tribo-Fluorination for

Oil-Less Hermetic Compressor Applications.

Front. Mech. Eng. 7:652001. doi: 10.3389/fmech.2021.652001
In the present work, we overview the multidisciplinary development of a regular, lubricated, hermetic compressor which works in an on-off cycle, circular motion, single-speed, many tribological contacts, into an innovative, linear motion, variable displacement, single tribological contact, oil-less hermetic compressor presenting high versatility in terms of refrigerator design, sustainability and improved efficiency. The original approach encompassed the development of new surface engineering procedures applying purpose-oriented phases to soft substrates. Particular emphasis is given to the in situ fluorination of the tribolayer formed in the piston-cylinder tribopair. Although chlorinated halocarbons (CFC) are efficient refrigerants from a thermodynamic point of view, they do have serious environmental implications that have forced the refrigeration industry to switch to more environmentally friendly hydrofluorocarbon (HFC) based refrigerants. The first and most successful alternative to the CFCs was tetrafluorocarbon, particularly tetrafluoroethane $\left(\mathrm{CF}_{3} \mathrm{CH}_{2} \mathrm{~F}\right)$, aka $\mathrm{R} 134 \mathrm{a}$ refrigerant. The current trend to downsizing mechanical systems, smaller clearances, and increased speeds leading to greater energy efficiencies associated with miscibility issues imposing the use of costly, fully synthetic lubricants with the R134a refrigerant gas led to the introduction of a new hermetic compressor design, the Wisemotion ${ }^{\circledR}$, the first, and until now, unique, oil-free hermetic compressor on the world market. In this context different types of multi-layers, their thickness, substrate material, processing routes, etc., have been studied and optimized. Si-rich hydrogenated DLC (a:C-H) presented enhanced tribological properties when tested under fluorine-rich atmospheres, and semi-industrial scale tests have been carried out to understand this point further. A homemade tribological emulator was developed allowing close-to-real tribopair, atmosphere, and imposed mechanical conditions used in an oil-free commercial hermetic compressor. The tests were carried under different stroke frequencies $(5,20$, and $40 \mathrm{~Hz})$ and atmospheres (R134a, ambient air, and argon). Results showed a strong influence of both atmosphere and stroke frequencies. The friction coefficients were significantly lower $(\sim 3.8 \mathrm{X})$ for the refrigerant gas atmosphere, attributed to the fluorine and highly disordered graphitic structures rich tribolayers. Under the high frequency $(40 \mathrm{~Hz})$, the energy input seems to be a deterrent to the formation of stable tribolayers, and the DLC coating shatters on the first few sliding meters.

Keywords: tribo-fluorination, tribological emulator, hydrogenated DLC, hermetic compressor, surface engineering 


\section{INTRODUCTION}

In total, $23 \%$ of the world's total energy consumption originates from tribological contacts, and the introduction of new technologies to improve the tribological efficiency of mechanical systems could amount to the annual saving of $1.4 \%$ of the Gross Domestic Product (GDP) on a global scale (Holmberg and Erdemir, 2017). The vast number ( 3 billion) of heat pump systems, air-conditioning, and refrigerators operating worldwide makes the refrigeration industry substantially contribute to this figure (International Institute of Refrigeration, 2015). Furthermore, household refrigeration represents $7.3 \%$ (and $17 \%$ for air conditioning) of residential energy consumption in the USA (U.S. Energy Information Administration, 2015), $30-40 \%$ in China (Cheng et al., 2011) and 30\% in Brazil (Boeng and Melo, 2014).

Several challenges require that the refrigeration industry keep a continuous innovation program by research and development to achieve high energy efficiency, high-reliability levels, low noise, and environmental regulations. For instance, the chlorofluorocarbons (CFCs) and hydrochlorofluorocarbons (HCFCs) are excellent refrigerant fluids. Yet, depending on their high global warming potential (GWP), the CFCs were banned from refrigeration applications with the signature of the Montreal Protocol by 197 countries in 1987. Even the HCFCs are in the process of being phased out. Table 1 presents details on some of the most common refrigerant fluids. The banishment of CFCs has driven humanity to the use of hydrofluorocarbons (HFCs), such as tetrafluoroethane $\left(\mathrm{CF}_{3} \mathrm{CH}_{2} \mathrm{~F}\right)$, aka $\mathrm{R} 134 \mathrm{a}$ refrigerant, and more recently, the environment-friendly hydrocarbon isobutene (R600a) (Cannaday and Polycarpou, 2005; de Mello et al., 2009). Tetrafluoroethane was the first and most successful alternative to the CFCs, and it's still widely used by the refrigeration industry, with applications varying from domestic refrigeration to automotive air conditioning.

Moreover, HFCs' incompatibilities with mineral oils have also induced a change from the mineral type to polyol ester (POE) or polyalkylene glycol (PAG) lubricants. Miniaturization and the worldwide tendency to reduce lubricant oils and their additives also affect the refrigeration industry. One of the major impacts is the increase in the severity of the tribological contacts in hermetic compressors. Besides, many compressor components operate in the boundary and mixed lubrication regimes (Pergande et al., 2004).

The regular hermetic compressor is a relatively complex mechanical system containing the electric motor, the mechanical kit, the lubricant, and the refrigerant in a hermetic chamber. It must have a very long lifetime (10 years warranty operating in extremely different conditions), stringent tolerances, and uses very low viscosity oils (in order to reduce viscous losses). The regular compressor, Figure 1A, works in an on-off cycle (high losses due to boundary and elastohydrodynamic lubrication regimes), circular motion, single speed, many tribological contacts, oil for lubrication.

The efficiency of hermetic compressors has increased incrementally for the last 40 years. In this context, solid lubrication and solid lubricants began to appear as potential choices for governing friction and wear in hermetic compressors. Additionally, since the thermodynamic efficiencies of refrigeration cycles increases, if the reduction in refrigerant flow is minimized or even eliminated, the interest in the evolution to oil-less compressors is undeniable (Solzak and Polycarpou, 2006). Therefore, in the mid-2000s, the scenario was opportune for developing an entirely new concept, which created a real paradigm shift, able to meet the latest environmental and tribological requirements, including a transition toward an oil-less compressor (Barbosa et al., 2015).

However, the classical tribological literature (Jost, 1990) clearly shows that a lubrication system modification is insufficient to produce real and relevant progress. To obtain a substantial and significant evolution we must consider all the multi/inter disciplinary aspects of tribology.

\section{DEVELOPMENT OF OIL-LESS HERMETIC COMPRESSORS}

\section{Wisemotion $^{\circledR}$}

Our research group participated intensively in a research and development program that culminated with introducing a new generation of oil-free hermetic compressors. Wisemotion ${ }^{\circledR}$ is

TABLE 1 | Lifetime, ozone depletion potential, halocarbon global warming potential, toxicity, and air flammability of main refrigerant fluids used in the refrigeration industry (Calm, 2000).

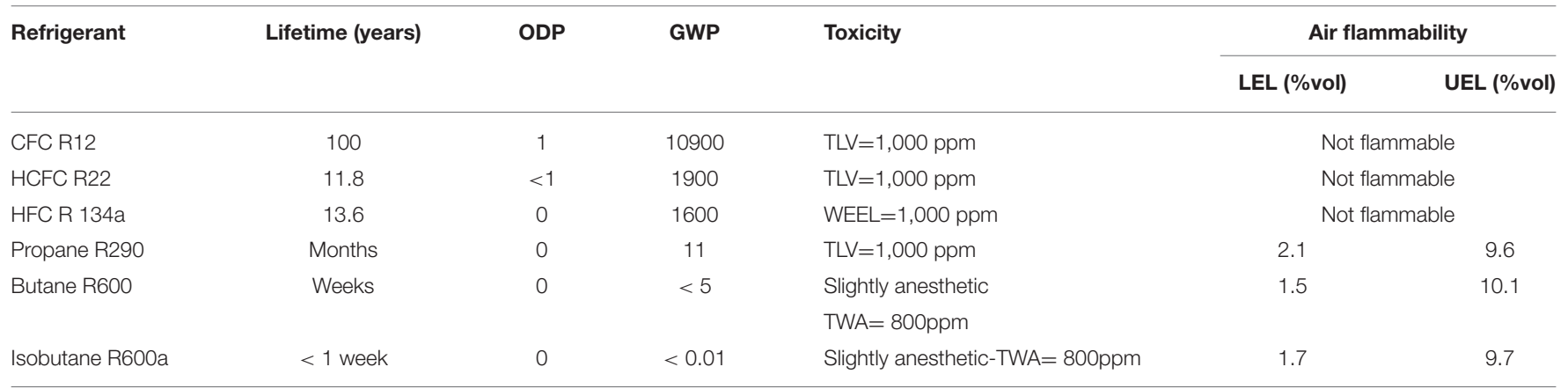

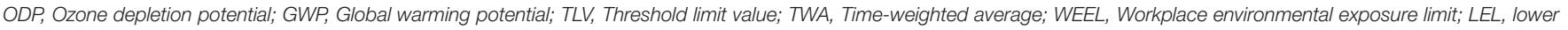
explosive limit; UEL, Upper explosive limit. 


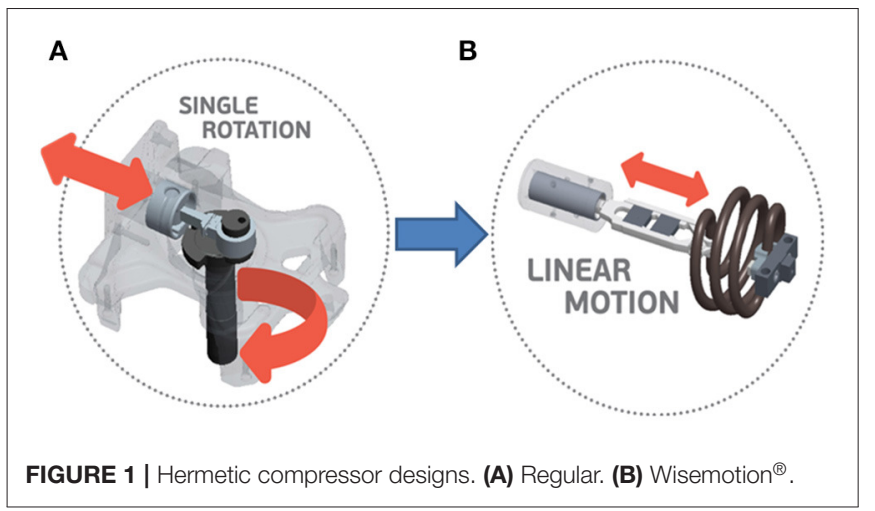

the first and, until now, unique, oil-free hermetic compressor on the market, and its development led to around 80 patents (Embraco, 2019). In contrast with regular compressors, the Wisemotion ${ }^{\circledR}$ mechanism, Figure 1B, performs only linear reciprocating movement and has a single tribological contact, the piston-cylinder pair that compresses the refrigerant fluid.

The Wisemotion ${ }^{\circledR}$ is smaller, much smaller than the previous generations. It means that it is possible to free up to 20 liters of cabinet space and to introduce new designs and architectures for refrigerators. The Wisemotion ${ }^{\circledR}$ is a top efficiency compressor and complies with some of today's strictest efficiency regulations. Additionally, it is very silent, about $10 \mathrm{~dB}$ quieter.

Our research group's main contribution is related to the unique tribological contact (piston-cylinder), particularly the piston.

Diverse inorganic materials (e.g., transition-metal, graphite, hexagonal boron nitride, boric acid, polymers, Diamond Like Carbon-DLC, etc.) can provide excellent lubrication (Lancaster, 1984; Lansdown, 1999; Erdemir, 2001). Common sense suggests using coatings, ensuring that the surface properties are sufficient to meet the tribological requirements (low friction and high wear resistance) of the system, as an ideal solution. For hard substrates such as hardened steels and cermet (WC-Co), the use of hard solid lubricant coatings has been widespread with great success (Rechberger et al., 1993; Holmberg and Matthews, 1994). However, spalling induced by high stresses generally promotes low adhesion in hard coatings-soft substrate systems associated with small and cheap components needed to be manufactured on a large and economically efficient scale (Holmberg and Matthews, 1994).

We started by carrying out a very comprehensive screening of commercially available coatings applied onto various soft substrates, Table 2.

This resulted in developing a new methodology to characterize coatings (de Mello and Binder, 2006); a very interesting, unpublished, proprietary ranking of the available coatings encompassing the average steady-state friction coefficient within the lubricious regime ( $\mu \leq 0.2$ ), the scuffing resistance, the micro-abrasion wear coefficient, and the characterization of the wear mechanisms.

Initially, a new methodology allowing short test time with good discrimination between multifunctional layers was developed (de Mello and Binder, 2006). The protocol is based
TABLE 2 | Commercially available solid lubricants based coatings.

\begin{tabular}{|c|c|c|}
\hline Denomination & Substrate & Coating \\
\hline A & Polytetrafluoroethylene & Polytetrafluoroethylene \\
\hline B & Commercial aluminum & DLC \\
\hline C & Commercial aluminum & $\mathrm{MoS}_{2}$ dispersed in inorganic binder \\
\hline D & Anodized aluminum & $\mathrm{MoS}_{2}$ dispersed in inorganic binder \\
\hline $\mathrm{E}$ & Commercial aluminum & $\mathrm{MoS}_{2}$ dispersed in organic binder \\
\hline $\mathrm{F}$ & Anodized aluminum & $\mathrm{MoS}_{2}$ dispersed in organic binder \\
\hline G & AISI 1020 steel & $\mathrm{A}: \mathrm{CH}$ \\
\hline $\mathrm{H}$ & Al 6351-T6 & $\mathrm{A}: \mathrm{CH}$ \\
\hline I & Gray cast iron & $\mathrm{A}: \mathrm{CH}$ \\
\hline J & AISI 1020 steel & Polyamide + PTFE \\
\hline K & $\mathrm{Al}-12 \% \mathrm{Si}$ & Polyamide + PTFE \\
\hline L & Al 6351-T6 & Polyamide + PTFE \\
\hline M & Anodized Al & Polyamide + PTFE \\
\hline N & Gray cast iron & Polyamide + PTFE \\
\hline O & Sintered Iron & Polyamide + PTFE \\
\hline $\mathrm{P}$ & AISI 1020 steel & MeC:DLC \\
\hline Q & Gray cast iron & MeC:DLC \\
\hline $\mathrm{R}$ & Sintered Iron & MeC:DLC \\
\hline S & - & PEEK+Graphite+PTFE \\
\hline $\mathrm{T}$ & AISI 1020 steel & $\mathrm{NiP}+\mathrm{PTFE}$ \\
\hline U & Al 6351-T6 & $\mathrm{NiP}+\mathrm{PTFE}$ \\
\hline V & Anodized Al & $\mathrm{NiP}+\mathrm{PTFE}$ \\
\hline$x$ & Gray cast iron & $\mathrm{NiP}+\mathrm{PTFE}$ \\
\hline Y & Sintered Iron & $\mathrm{NiP}+\mathrm{PTFE}$ \\
\hline Z & AISI 1020 steel & Me:MoS 2 \\
\hline AA & Al 6351-T6 & Me:MoS 2 \\
\hline BB & Al-12\%Si & Me:MoS 2 \\
\hline CC & Gray cast iron & Me:MoS 2 \\
\hline DD & Sintered Iron & $\mathrm{Me}: \mathrm{MoS}_{2}$ \\
\hline
\end{tabular}

on the incremental normal load technique. By increasing the normal load in increments at a constant time interval, the surface durability of both the hard layer and the solid lubricant coating is determined (de Mello and Binder, 2006). Besides, the average steady-state friction coefficient within the lubricious regime $(\mu$ $<0.2$ ) is obtained.

Again, the literature provides judicious advice. Donnet and Erdemir (2004) synthesizing more than 2,000 published papers, stated that: there exists no single solid lubricant that can provide both low friction and wear over broad substrate hardness, temperatures, and environments use conditions. Multifunctional surface engineering processing route combining customized layers applied to soft substrates allows the combination of high wear resistance, load support, and low friction coefficient (de Mello and Binder, 2006). Our main conclusions pointed to multilayer, multipurpose coatings, with hydrogenated DLC as the low friction top layer.

Diamond-like carbon (DLC) coatings are defined as a metastable form of amorphous carbon (a-C) or hydrogenated amorphous carbon $(\mathrm{a}-\mathrm{C}: \mathrm{H})$ prepared by a wide variety of PVD and CVD techniques. The film structure and properties are 
determined by the Hydrogen content and the relative proportion of sp2 and sp3 carbon hybridizations.

With excellent wear resistance, DLC-based tribosystems have very low dry friction coefficients, among the lowest $(0.1<$ $\mu<0.2$ ) reported in the literature (Brookes and Brookes, 1991; Feng and Field, 1991; Miyoshi, 1995; Erdemir et al., 2000a,b; Field, 2012). Values as low as 0.01 , associated with extremely low wear rates $\left(10^{-9}-10^{-10} \mathrm{~mm}^{3} / \mathrm{N} \mathrm{m}\right)$ are frequently reported (Erdemir et al., 2000a,b; Donnet and Erdemir, 2008) which are (Grill, 1997; Erdemir et al., 2000a,b; Donnet and Erdemir, 2008). Si addition to DLC (Si-DLC) besides improving surface roughness and adhesion strength (Oguri and Arai, 1991) induces low friction, high durability, and stability against humidity and temperature.

The nature of the substrate, DLC and load-bearing films, their respective thicknesses, the nature of the counter faces, together with the environmental conditions, are of paramount importance and play an essential role in friction and wear control of DLCbased tribosystems (Franks et al., 1990; Oguri and Arai, 1991; Donnet and Grill, 1997; Voevodin et al., 1999; Erdemir et al., 2000a,b; Erdemir, 2001; Ohana et al., 2004a,b; Vercammen et al., 2004; Cho et al., 2005; Donnet and Erdemir, 2008).

In this sense, the genesis, stability, and nature of a tribolayer on the sliding contact appears as the key for obtaining low friction and long wear life in most solid-lubricated systems. The nature of the counter faces can significantly influence the size and nature of the transfer layer (both of which sometimes differ from the initial composition of the film) (Erdemir, 2001).

In this context, our group has been dealing with different kinds of DLC as low friction top most layer, different nitrides as load bearing/wear resistant layer, the thickness of these layers, low carbon steel and cast iron (gray and nodular) as substrate, the nature and geometry of the counterbody and, of course, the surrounding atmosphere.

\section{Layers Nature and Thicknesses}

Lara et al. extensively analyzed the effect of the thickness of DLC and CrN layers on hardness, scratch resistance, interface adhesion and sliding wear of proprietary magnetron sputtered diode multifunctional CrN-Si-rich DLC coatings deposited onto soft (120 HV) AISI 1,020 carbon steel substrates (de Mello, 1983; Lara and De Mello, 2012; Lara et al., 2015). The sliding wear tests, in particular, used a 3D triboscopic maps based original approach.

Averaging the measured variable after steady-state conditions are reached is the leading technic used for data evaluation of tribological tests. Triboscopy, initially proposed by Belin (1993) and recently enhanced by dos Santos et al. (2015) is another potential and versatile approach that allows the location of microscopic tribological events as well as to know their evolution while providing information with both local details and global evolution of the tribological phenomena (Zhu et al., 2010).

The thicknesses of both layers were varied and the specimens could be grouped into two families: thicker and thinner coatings. Previous works extensively characterize the main coatings characteristics, e.g., Raman spectroscopy, thickness, mechanical properties of the coating layers and substrate (Lara and De Mello, 2012; Lara et al., 2015). The ball-on-flat reciprocating sliding tests were carried out in a tribometer Plint TE 67 using a frequency of $2 \mathrm{~Hz}$ and a stroke length of $10 \mathrm{~mm}$ at room temperature conditions (Lara et al., 2015).

Incremental load ( $7 \mathrm{~N}$ every $10 \mathrm{~min}$ ) 3D triboscopic maps are shown in Figure 2. No significant variation could be observed for the durability of the coatings (Lara et al., 2015). However, thinner coatings presented the lowest average friction coefficient $(0.07$ vs. 0.11 respectively) within the lubricious regime. For thicker coatings, the very first friction coefficient (0.07) progressively increases as the normal load is incremented up to $105 \mathrm{~N}$ when the lubricious regime ends (Figure 2A). In contrast, for thinner coatings, the friction coefficient starts around 0.1 , stabilizes at $\sim 0.07$ up to $112 \mathrm{~N}$ (Figure 2B).

Contact potentials for both samples (Figures 2C,D) are initially high (around $50 \mathrm{mV}$ ), which is typical of DLC-metal insulated contacts, and then decrease to values around zero, when the friction coefficient rises above 0.2 , indicating a noninsulating contact. Very good matching was found between the friction coefficient maps and the contact potential maps for all the tested samples.

Typical friction triboscopic maps for the constant load tests showed that the family of thinner coatings presented a reasonably stable friction coefficient throughout the test, with few oscillations. In contrast, the thicker coatings presented higher friction coefficients in the region where spalling of the DLC coating could be detected, Figure 3 .

Wear rates on the thinner layers were up to five times lower than the thicker ones, on the samples and their associated counterbodies. Thus, even though both layers have presented similar friction coefficients and durabilities within the lubricious regime, the thinner coatings presented better overall tribological behavior.

To analyze the influence of the coating thickness on the stress distribution, the results above were compared to, and are in accordance with, indentation tests and simulations made using the commercial software FilmDoctor ${ }^{\circledR}$ (Lara and De Mello, 2015; Lara et al., 2015).

To further understand the influence of the nature of the loadbearing layer, we developed, using Plasma Enhanced Chemical Vapor Deposition (PECVD), an in house proprietary coating registered as $\mathrm{CHИ}^{\circledR}$ (Shioga et al., 2016). The multifunctional coating consisted of a load-bearing layer (plasma nitride layer), and a low friction layer (DLC) deposited onto soft, low carbon steel (AISI 1,020).

Plasma nitriding is a diffusive thermo-chemical treatment that increases the surface hardness in steels and metallic alloys (Spalvins, 1983; Maliska, 1995; Pinedo and Monteiro, 2001; de Mello et al., 2010; Zhu et al., 2010).

Plasma nitriding processes generate little waste, require few consumables, and are easier to control than other nitriding processes (Spalvins, 1983). Additionally, the costs of the process comply with the industry requirements (Spalvins, 1983; Maliska, 1995; Pinedo and Monteiro, 2001; Zhu et al., 2010). Different nitride phases can be obtained by tuning the control variables for the plasma nitriding. Literature indicates that different gas 

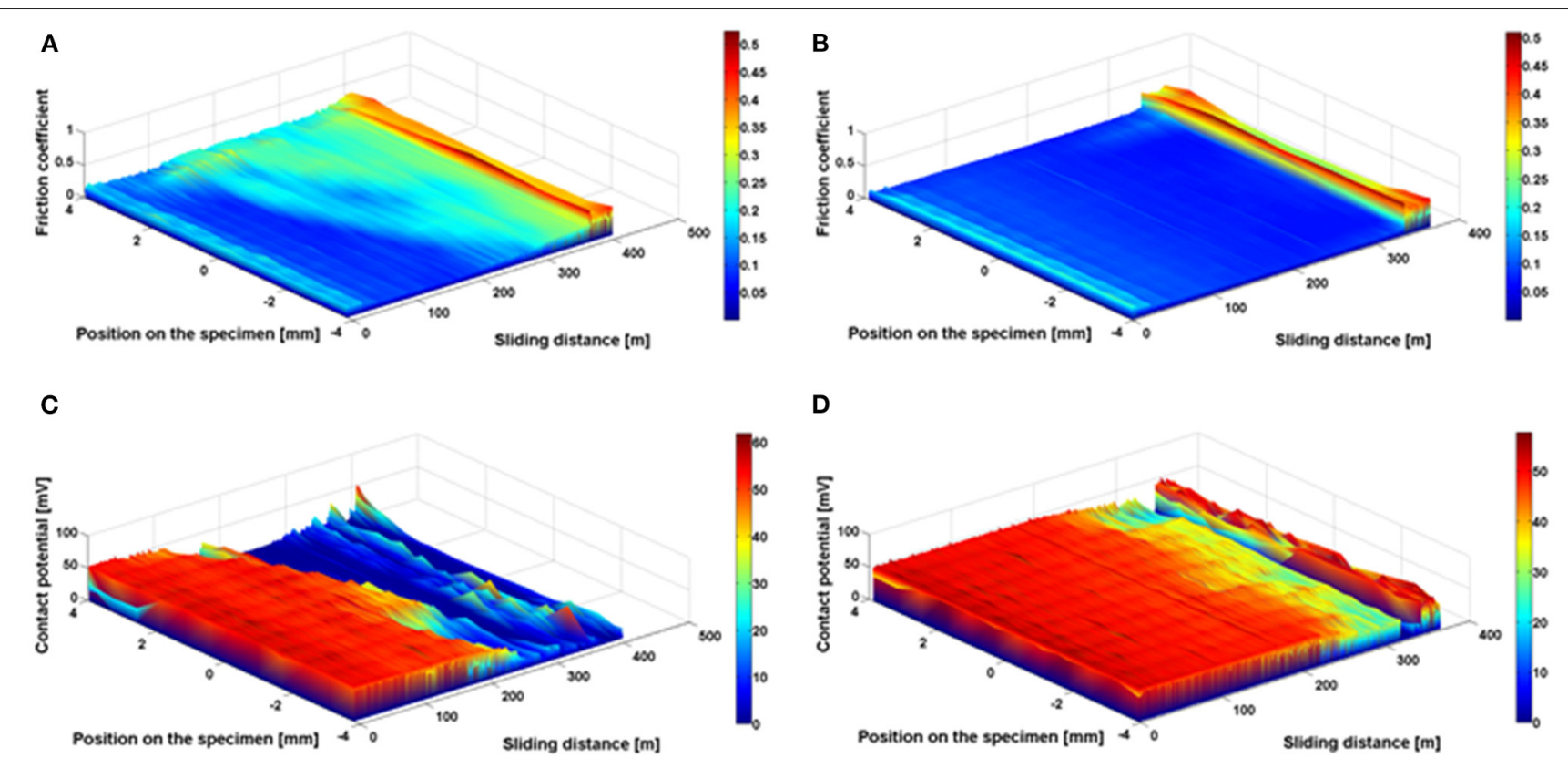

E

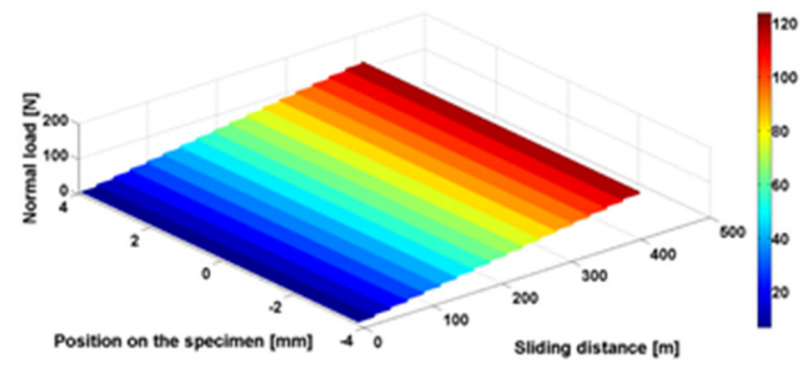

FIGURE 2 | Typical triboscopic maps for the durability tests. (A) Friction coefficient, thick layers. (B) Friction coefficient, thin layers. (C) Contact potential, thick layers; (D) contact potential, thin layers, (E) normal load map (Lara et al., 2015).

mixtures used in the process can originate different hardness profiles and case depths (Karakan et al., 2002).

Three distinct nitride layers were synthesized: one compound layer mostly formed by an $\varepsilon\left(\mathrm{Fe}_{2-3} \mathrm{~N}\right)$ phase, one compound layer predominantly $\gamma^{\prime}(\mathrm{Fe} 4 \mathrm{~N})$, and one diffusion layer. All three surfaces received the same DLC coating. Shioga et al. depict in detail the processes and characterization techniques used in the work (Shioga et al., 2016).

The adhesion of the coatings was determined using an improved version of the technique described by the German standard VDI3198 (VDI, 1992). DLC layers on top of the composite $\varepsilon$ and $\gamma$ ' layers were the most resistant to delamination. In contrast, the delamination of the DLC layers deposited on the diffusion layers was almost two times larger.

The tribological performance of multipurpose coatings (composed of a DLC and a nitride Layer) was analyzed via the durability test method proposed by de Mello and Binder (de Mello and Binder, 2006). All specimens behaved similarly in the lubricious regime. Nevertheless, a significant variation was found in the friction coefficient as well as in the extent of the lubricious regime. The DLC deposited over the diffusion layer performed the best, with the durability of 13.000 N.m and friction coefficients around 0.05 (the lowest). The g' layer coated with DLC demonstrated the worst performance; tests performed on that system have failed in the first few minutes, presenting durability of 600 N.m. The average friction coefficient was the highest (0.2).

Regrettably, the topographical features of the samples are altered by the plasma nitriding process, which usually increases the roughness to the micrometer range (Jeong and Kim, 2001; Dalibon et al., 2013), directly affecting the mechanical support for the DLC (Karakan et al., 2002; Masuko et al., 2013), and is strongly influenced by the hollow cathode effect (HCE), as recently demonstrated by Lamim et al. (2019). The initial roughness also influenced the case depths of the nitride layers (Singh et al., 2006). 


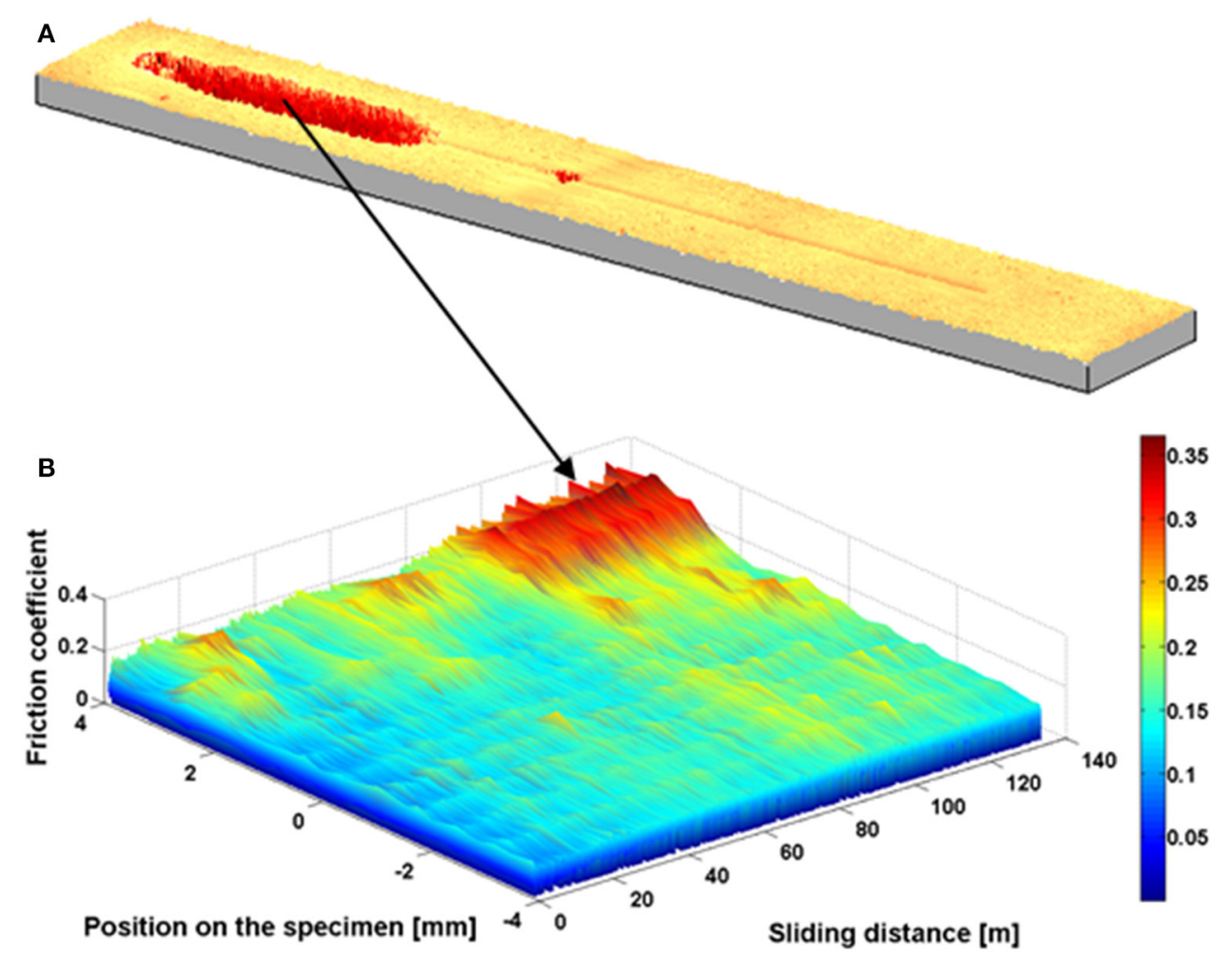

FIGURE 3 | Typical constant load sliding test, 1 h, 7N. (A) Laser interferometry image of the wear track; (B) friction 3D triboscopic map (Lara et al., 2015).

\section{Substrate}

\section{Substrate Surface Finishing}

To understand how the surface finishing (five different conditions) of a soft substrate influences the tribological behavior of hydrogenated amorphous carbon (a-C:H) films, DLC coating was applied on plasma-nitrided low carbon steel substrates. Both processes happened in a single PECVD batch (Soprano et al., 2018). The mechanical properties and bonding structures of the a-C:H films are negligibly affected by the substrate topography. Two groups of samples were originated from the deposition process, regarding their topography: (a) Rough $(0.17<\mathrm{Sq}<0.23 \mu \mathrm{m})$ and (b) Smooth $(0.08<\mathrm{Sq}<0.11 \mu \mathrm{m})$.

Incremental normal load reciprocating dry sliding tests in ambient air revealed friction coefficients of 0.09 (Rough) and 0.05 (Smooth), which suggests that the formation and stability of tribolayers are impaired on the rougher substrates, leading to higher friction coefficients. For smoother substrate surfaces, graphite-rich tribolayers were formed in the counter bodies yielding substantially lower friction coefficient values $(\sim 0.04)$ but higher wear of the coating. Since plasma nitriding treatment notably alters the surface topography of smooth surfaces, producing substrate surface finishing beyond $\mathrm{Sq}=0.06 \mu \mathrm{m}$ to obtain friction coefficients ranging from 0.04 to 0.06 is pointless.

Enabling the use of DLC multifunctional coatings on lowercost substrates while preserving the tribological and mechanical performance of the system is undoubtedly a current challenge in the industry and demands additional research. Gray cast irons
(GCI) and nodular cast irons (NCI) arise as potential candidates to fulfill the demand due to their vast industrial applications such as large stamping tools (Corbella et al., 2004), automotive parts (Sánchez-López et al., 2003; Podgornik et al., 2008; Maurizi et al., 2014), household appliances industry (Agarwal et al., 2013), among others. Despite that, a small number of studies concerning GCI and NCI tribological behavior when used as a substrate for DLC coating was found in the literature (Andújar et al., 2003; Corbella et al., 2004; Podgornik et al., 2008).

\section{Substrate Nature}

To help bridge this gap, a tribological investigation was performed on a-C:H films deposited onto nitrided gray and nodular cast irons. Significant topographical differences between both substrate materials were induced mainly by the nitriding process, where wedges of more than $5 \mu \mathrm{m}$ formed on GCI nearsurface graphite flakes, Figure 4 (Giacomelli et al., 2017). These wedges played a paramount role in the tribological behavior. They were created in regions where the graphite flakes were located near the surface, and they frequently covered entirely the graphite that was previously exposed (Figure 4e). After DLC deposition ( $2.5 \mu \mathrm{m}$ thick), little modification was observed compared to the nitrided surface, as shown by the very similar topographic parameters.

Coated samples of both substrates presented similar scuffing resistance when tested under incremental load (reciprocating). However, coated GCI samples systematically showed an 

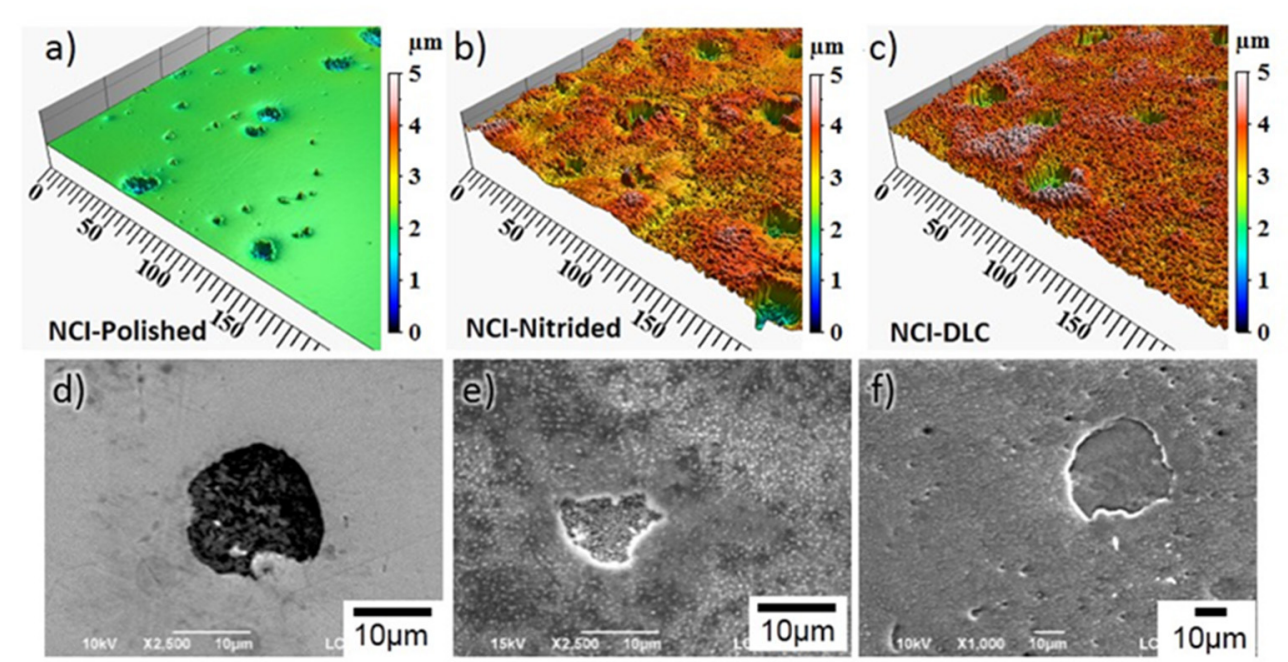

FIGURE 4 | Topography evolution with WLI and SEM analyzes for Gray Cast Iron (GCl), polished (a,d), nitrided (b,e) and with DLC (c,f) (Giacomelli et al., 2017).

unexpected low friction coefficient during most of the lubricious regime (0.06). In contrast, the NCI presented a steady 0.15 friction coefficient during the whole extent of the durability tests. The presence of tribolayers covering a considerable extension of the wear marks governs the low friction coefficient of coated GCI. Such phenomenon is explained by the highly disordered graphitic structure of the tribolayers, confirmed via Raman analysis and reported to provide low shear strength. Another consequence of the formation of these tribolayers is the smoothening of the contact region, reducing the contact severity of the asperities found on coated GCI samples. This effect contributes to the maintenance of the system in a self-lubricating regime for more extended periods. On the other hand, NCI-LR interrupted test revealed that such tribolayers were not found since the few debris particles available were piled-up inside valleys, not effectively contributing to a reduction in friction coefficient in that case. Finally, the wear volume of NCI was 2.4 times lower once there was not a brittle wear mechanism like the one found for coated GCI.

As evidenced, graphite regions near the surface in both substrates play a key role in thin-film applications, especially considering these graphite sites represent mechanical voids regardless of their morphology and, thus, spalling of coatings such as DLC may appear in these regions during tribological contact (Salvaro et al., 2017). Due to the cruciality of this aspect, surface treatments were developed by different research groups to remove all near-surface graphite before the nitriding of similar materials (Karamiş and Yildizli, 2010; Zenker et al., 2013). Another critical issue is the relatively low hardness of cast iron metallic matrixes, which induced the necessity of the development of suitable mechanical support layers, being the nitriding of ferrous substrates a commonly used solution (Agarwal et al., 2013; Ebrahimi et al., 2015; Shioga et al., 2016; Giacomelli et al., 2017). However, as reported, the plasma nitriding of gray cast irons strongly affects its topography, generating wedge-like features (Rolinski et al., 2007, 2009). Factors such as graphite flakes orientation relative to the surface, volumetric expansion during the nitride layers formation, weak graphite-matrix adhesion and nitrided layer interruption by graphite would play a vital role in the formation of wedges (de Mello, 1983; Dalibon et al., 2013; Shioga et al., 2016). In Figure 5, a scheme for each graphite flake orientation is shown. The most critical case is when the graphite flake is skewed to the surface. Weak graphite-matrix interaction, interruption of the nitride layer and an intense local volumetric expansion happen simultaneously, systematically leading to the formation of wedges (Figure 5B). If the graphite flake is vertical, although there is an interruption of the nitride layer, no intense nitriding occurs since there is no barrier for the diffusion of nitrogen. Thus, less volumetric expansion occurs locally and no wedge formation was observed (Figure 5C). When the graphite flake is parallel to the surface, there is no interruption of the nitride layer, inhibiting the formation of wedges (Figure 5D). However, these locations can easily nucleate defects on the surface (de Mello, 1983).

\section{Counterbody Geometry and Nature}

Finally, the effect of the counterbody geometry and nature and the potentiality of using multifunctional coatings as an auxiliary mechanism in mixed lubrication were evaluated (Salvaro et al., 2017).

A multifunctional coating strategy was applied using a nitride layer for mechanical support, followed by a silicon-rich interlayer to enhance the adhesion of the uppermost a-C:H coating. Cylinder-plane tribopair configurations with coated and uncoated GCI surfaces were evaluated under lubricated and dry conditions. The low viscosity $(4.2 \mathrm{cSt})$, linear alkylbenzene oil associated with BTP anti-wear additive was used as a lubricant. Four distinct reciprocating cylinder-plane configurations (horizontal cylinder sliding without rolling against a plane) were tested in dry and lubricated conditions: DLC coated plane on a 


\section{A}

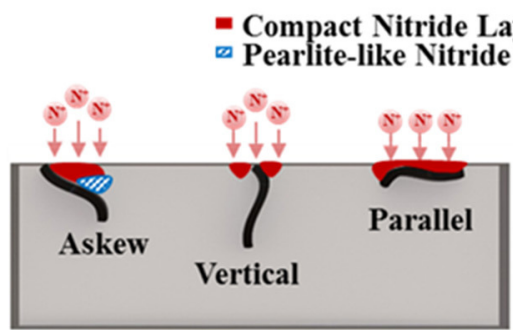

C

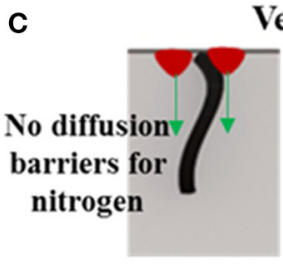

Vertical

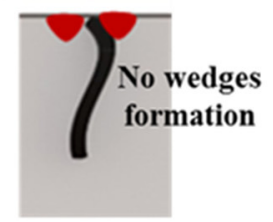

B

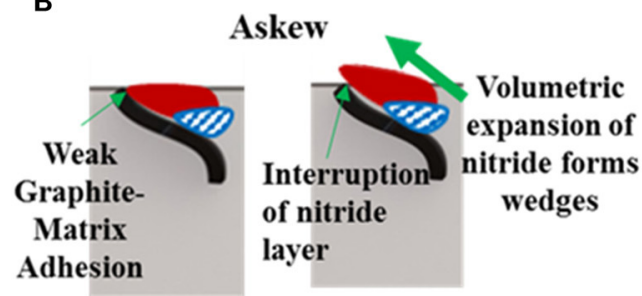

D

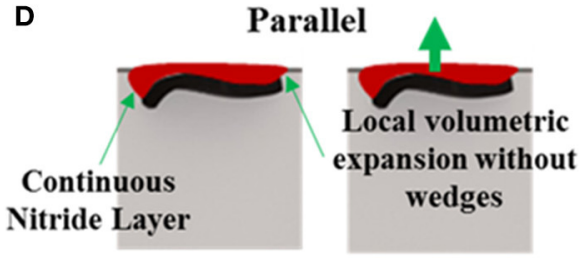

FIGURE 5 | Scheme showing different situations for the wedges formation (A). Particular cases of graphite flakes orientation to the surface. (B) Askew, (C) vertical, and (D) parallel (Giacomelli et al., 2017).

GCI cylinder, a DLC coated cylinder vs. a GCI plane, a DLC coated cylinder vs. a DLC coated plane, and a GCI uncoated cylinder against a GCI uncoated plane (Salvaro et al., 2017).

In general, GCI surfaces presented ductile abrasive wear, while the DLC surfaces exhibited brittle wear (spalling) regardless of the test condition (dry or oil-lubricated). For dry tests, the smoothening of the contacts generated wear debris on the contact, favoring the genesis of tribofilms that govern the tribological behavior. Additionally, for both coated and uncoated horizontal cylinder surfaces, the DLC presence on the plane surface increases the dry friction coefficient. For lubricated tests, the formation of a BTP-rich on the uncoated surfaces played a crucial role in governing the wear rate.

As mentioned, the surrounding environment is a fundamental factor in the genesis and establishment of the tribolayer, which in turn, governs the tribological behavior. Consequently, a great effort was dedicated to understanding how the environment (air, CO2, Argon, R134a, and R600a) affects the tribological performance of a proprietary, Si-rich multilayer DLC coating deposited on soft AISI 1020 steel.

\section{Surrounding Atmosphere}

Finely ground $(\mathrm{Sq}=0.23 \pm 0.025 \mu \mathrm{m})$ AISI 1,020 soft steel disks were coated with multifunctional CrN-Si-rich DLC by magnetron sputtering PVD. The tribological tests were conducted in a specially designed high-pressure tribometer (HPT) to simulate the hermetic refrigeration compressor condition. Yoon et al. (1998) present a detailed HPT description. In contrast, the tribological test procedures and specimens' features were well detailed and explained in a previous paper (de Mello et al., 2009).

To assess the effect of a typical hermetic compressor refrigerant atmosphere, dry (unlubricated) tests were carried out in $\mathrm{CO}_{2}$ and $\mathrm{R} 600 \mathrm{a}$ at $0.1 \mathrm{MPa}$ environmental pressure. As a reference, identical tribological tests were performed in unpressurized laboratory ambient air $(45 \%$ relative humidity, $20^{\circledR} \mathrm{C}$ ).

Tests performed with R600a presented the best wear performance of both specimens and counter-bodies, along with the lowest mean friction coefficient. In contrast, air atmosphere induced the highest ones (234, 52, and 266\% higher, respectively). The wear mechanisms act mainly on the prominent asperities of the topography. There was a clear inverse correlation between the tribological behavior and surface topography as evidenced by the reduced peak height (Spk) surface parameter (derived from the Abbot and Firestone curve) and the surface evolution to sharper and negatively asymmetrical (as compared to the Gaussian distribution), as observed in the morphological space (de Mello, 1983).

EDS and Raman analyzes do not present significant differences between wear marks on the specimens. Therefore, the authors assumed that the tribolayers on the counter bodies play a crucial role in the tribopair behavior. All Raman spectra presented smaller bands at lower Raman shift. These bands can be related to the iron oxide formed due to the tribochemical reaction of the counterbody (steel pin) with the surrounding atmosphere.

The tests with R600a refrigerant gas presented typical $G$ and $\mathrm{D}$ bands. In contrast, spectra related to $\mathrm{CO}_{2}$ and air have shown only a broad peak at around 1,300 cm-1; e.g., the $\mathrm{G}$ band was not detected. Since this peak could not be unambiguously assigned (de Mello et al., 2009), the superior tribological performance induced by the R600a atmosphere is likely to be due to the presence of the graphitic structure in the tribolayers as indicated by the presence of a strong G-band in the spectra.

In other studies (Silverio et al., 2010, 2016) using a different environmental chamber, we compared the influence of HFCderived (R134-a) atmosphere on the tribological behavior of the same multi-purpose coating. There was a clear increase in surface durability. This was attributed to incorporating fluorine 


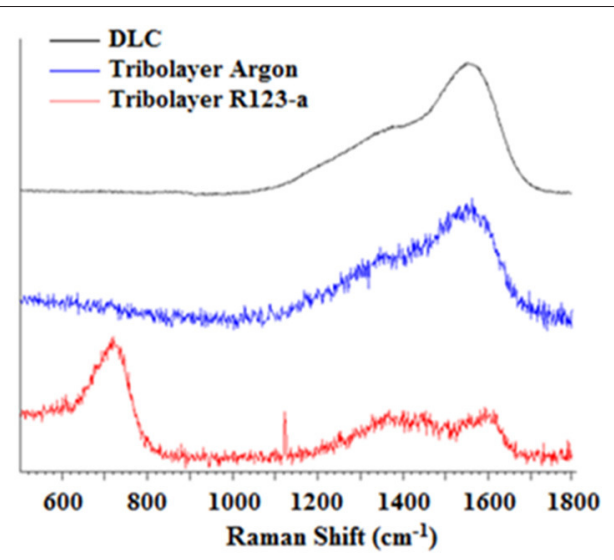

FIGURE 6 | Comparison of the Raman spectra of tribolayers obtained in atmospheres of argon, R134-a and the original DLC (Barbosa et al., 2015).

(from the gas $\mathrm{CH}_{2}-\mathrm{FCF}_{3}$ ) into the tribolayer present in the counterbody, as evidenced by the EDS analysis.

This trend was confirmed by another more fundamental and in-depth study (Barbosa et al., 2015). We studied, using scanning electron microscopy (SEM), micro-Raman spectroscopy, and glow discharge optical emission spectroscopy (GDOES), the physical-chemistry of the tribolayers formed on AISI 304 stainless steel rubbed against a 52,100 cylinder coated with DLC under a special (refrigerant R134a) atmosphere. The DLC coating was obtained via PECVD in a semi-industrial scale reactor. The DLC film was $2.5 \mu \mathrm{m}$ thick and presented a silicon-rich interlayer to improve adhesion to the substrate. The tribological tests were performed in a tailor-made, high-stiffness tribometer containing a hermetic chamber to control the atmosphere, as well-described in a previous paper (Barbosa, 2014).

The noisy Raman spectra associated with tribolayer produced in tests carried out in the R134a atmosphere exhibit the G and $\mathrm{D}$ bands characteristic of DLC. Also, a low Raman shift $\left(720 \mathrm{~cm}^{-1}\right)$ can be observed. It was attributed to chromite, an iron chromium oxide $\left(\mathrm{FeCr}_{2} \mathrm{O}_{4}\right)$. Besides, the spectra showed a sharp peak at around $1,120 \mathrm{~cm}^{-1}$ that does not coincide with any of the possible usually formed iron oxides (de Mello et al., 2009). A set of new tests were carried out using argon as the surrounding atmosphere to clarify this point. The results show a high similarity between the Raman signal obtained and those of the original DLC coating (Figure 6). Therefore, the peak at 11,20 $\mathrm{cm}^{-1}$ was not detected. According to the literature, the DLC fluorine doping increases the $\mathrm{I}_{\mathrm{D}} / \mathrm{I}_{\mathrm{G}}$ ratio, i.e., the $\mathrm{D}$ band intensity increases relatively to $\mathrm{G}$ band, which is evident when compared the spectra (Yu et al., 2003; Marciano et al., 2010). Another result supporting this hypothesis is the higher friction coefficient presented by the tests carried out in the argon atmosphere compared to R134a tests ( 0.18 and 0.12 , respectively), clearly indicating the potentiality of the in-situ fluorination of tribolayers formed in fluorine-rich atmospheres, such as R134a.

In synthesis, tribological properties of DLCs are usually governed by the formation, stability, and composition of tribolayers which, in turn, are a function of the contact parameters, especially pressures and temperatures (Holmberg et al., 1998; Barbosa et al., 2015; Salvaro et al., 2016, 2017; Wong and Tung, 2016). They result from continuous reactions between the surfaces in tribological contact and the surrounding atmosphere, lubricants, and even contaminants.

The tribolayers contain high disordered graphite (solid lubricant), which is derived from the hydrogen diffusion from the DLC matrix at around $400^{\circ} \mathrm{C}$ (temperature achieved due to the contact action), resulting in the local change from $\mathrm{sp}^{3}$ to $\mathrm{sp}^{2}$ carbon-carbon bonds structure (graphite) on the tribological contact (Liu et al., 1996; Liu and Meletis, 1997).

To better understand this crucial point, e.g., the genesis, stability, and composition of tribolayers, the long term stability of tribolayers were evaluated. The test duration influence (180, $500,1,000$, and $2,500 \mathrm{~h}$ ) on the characteristics of tribolayers formed in DLC-stainless steel tribopairs tested under a controlled atmosphere (R134a refrigerant gas) was analyzed (Salvaro et al., 2016). The dry tests were conducted using a proprietary, high frequency $(350 \mathrm{~Hz})$, specially developed emulator which uses, instead of laboratory specimens, real components as tribopair (stainless steel cylinders and DLC coated pistons).

Tribolayers composed of elements originating from mutual transfer material transfers and oxides were found. Additionally, their thicknesses ranged from 100 to $500 \mathrm{~nm}$ and were more evident on the stainless steel surface. Thicker tribolayers were found on the stainless steel cylinder, and thinner ones on the DLC coated piston. From the chemical and dimensional stability point of view, the tribolayers reach a stable state after $1,000 \mathrm{~h}$ testing. It was suggested that a mutual transfer of certain elements between the two surfaces is at the origin of mutual destruction and formation of tribolayers until a stable state was eventually reached (Salvaro et al., 2016).

Doping DLCs with some elements, such as hydrogen, silicon, molybdenum, and fluorine, can further enhance their tribological properties. Silicon is one of de most common doping elements for diamond-like carbon coatings (Si-DLC), providing outstanding properties such as low friction coefficient, high scuffing resistance, and stability against humidity and temperature. Moreover, according to Oguri and Arai (1991), Si addition enhance surface roughness and improves the adhesion strength of the DLC. Fluorination is reported as a consequence of higher inertness and lubricity to induce lower friction coefficients and high wear resistance than other types of DLC, such as a-C:H (Sung et al., 2009). Such effect is promoted by the enhancement of the hydrophobic behavior of the film and the decrease of its surface-free energy, which is a common way to evaluate the antistickiness behavior of the materials (Donnet et al., 1994; Trojan et al., 1994). According to Wang et al. (2013) fluorine termination layers on the DLC film can provide lower friction coefficients due to the large filled electron density coverage. Thus, the friction between similar F-terminated DLC film surfaces is governed by repulsive electronic interactions.

Our results show, unequivocally, the great potential of in situ tribo-fluorination in situ as friction and wear control agent in DLC-steel pairs when in a fluorine-rich atmosphere, the object of this paper. 


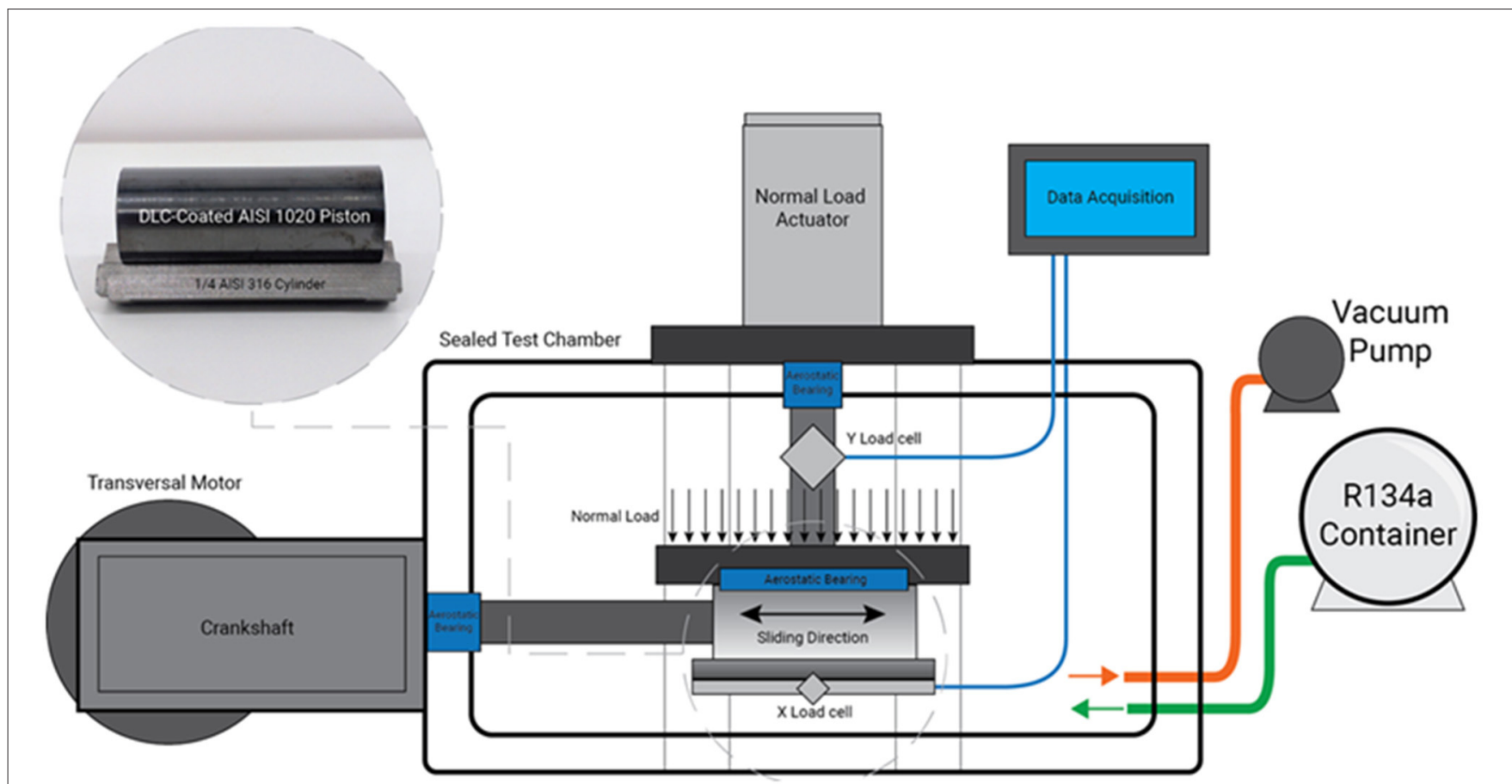

FIGURE 7 | Testing system overview. Tribopair zoomed in.

\section{IN SITU TRIBO-FLUORINATION}

This study evaluated the role of a fluorine-rich atmosphere on the tribological behavior of a tribopair formed by a DLC-coated piston sliding against a stainless-steel cylinder of an oil-free hermetic compressor. To simulate close-to-real operation conditions, it was used a homemade tribological emulator. Tribological tests were performed with real mechanical components as tribopairs. With such a kind of apparatus, it was possible to achieve frequencies closer to those of a hermetic compressor while also controlling the testing atmosphere.

\section{Materials and Methods Tribological Testing}

A homemade reciprocating tribological emulator was used to test Si-rich DLC-coated AISI 1020 pistons vs. $1 / 4$ AISI 316 cylinders. Both components originate from a hermetic oil-less compressor assembly. Figure 7 presents a schematic diagram of the tribological emulator and highlights the piston-cylinder tribopair. The emulator is programmed in such a way that the transversal sliding only starts when the normal load has been fully applied and the test chamber is above atmospheric pressure. The transversal motor achieves frequencies up to $60 \mathrm{~Hz}$ in $<1 \mathrm{~s}$ and the torque remains constant.

Tribological dry sliding reciprocating tests were performed using the parameters shown in Table 3 . The atmosphere and frequencies are presented in Table 4. Five equal tests, monitoring the friction coefficient, were performed for each condition. An automatic vacuum system was used to purge the testing chamber before pressurizing it with gas (ambient air or R134a). Before and
TABLE 3 | Imposed test conditions.

\begin{tabular}{lc}
\hline Stroke & $8 \mathrm{~mm}$ \\
Sliding distance & $120 \mathrm{~m}$ \\
Normal load & $100 \mathrm{~N}$ \\
Room temperature & $22^{\circ} \mathrm{C}$ \\
\hline
\end{tabular}

TABLE 4 | Test frequencies and atmosphere.

\begin{tabular}{lcccc}
\hline Atmosphere & Ambient air & R134a & R134a & R134a \\
\hline Stroke frequency & $5 \mathrm{~Hz}$ & $5 \mathrm{~Hz}$ & $20 \mathrm{~Hz}$ & $40 \mathrm{~Hz}$ \\
\hline
\end{tabular}

after tests, the DLC-coated pistons and cylinders were cleaned with acetone were cleaned in an ultrasonic bath for $15 \mathrm{~min}$ and then dried in a warm airflow.

\section{Characterization}

Topographical data of DLC-coated pistons and stainlesssteel cylinders were obtained using white-light interferometry (WLI) (Zygo NewView 7300) and then processed using the MountainsMap ${ }^{\circledR}$ Universal 7.1 software. Sa and Sq surface roughness parameters and texture isotropy were acquired by the following operation sequence:

i Filling in non-measured points $(<1 \%)$.

ii Leveling.

iii Remove the form. 


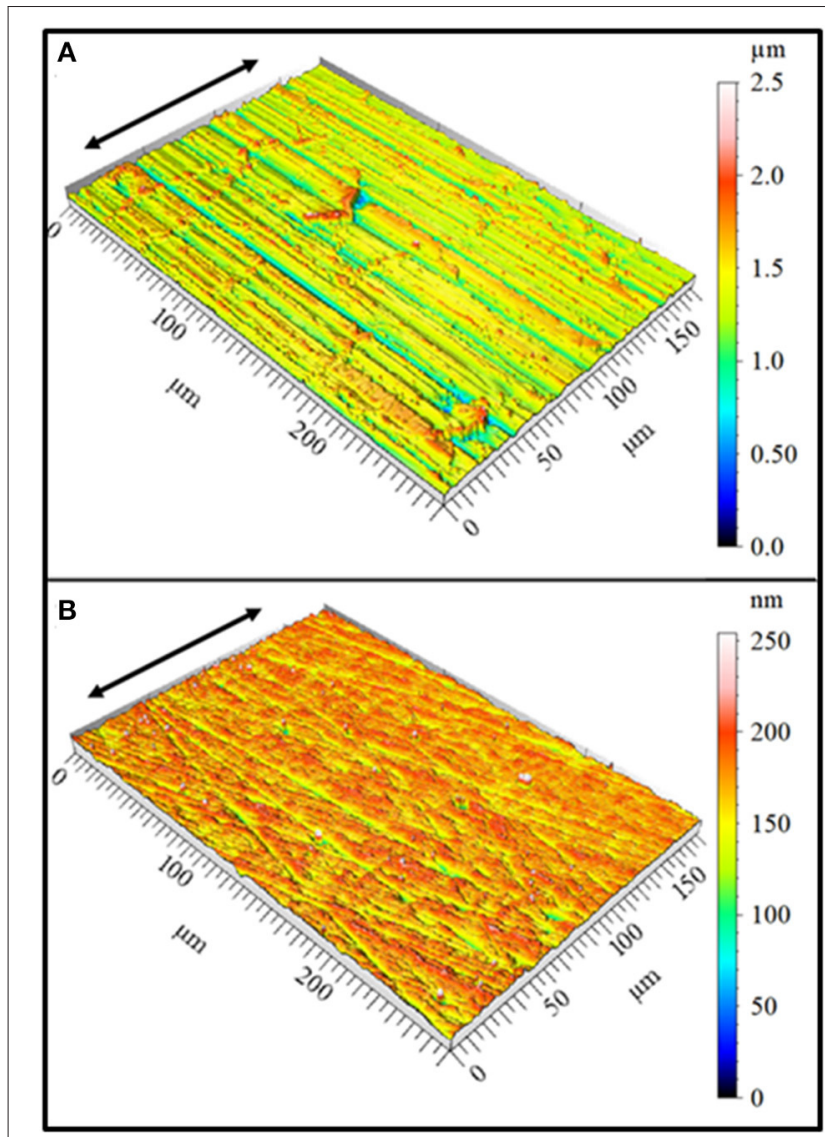

FIGURE 8 | Topography before tribological tests. (A) Cylinder.

(B) Coated piston.

iv Standard Gaussian filter with an $80 \mu \mathrm{m}$ cut-off to separate roughness and waviness.

Five samples of $0.05 \mathrm{~mm}^{2}$ each were analyzed for each material, and the average value and standard deviation were obtained. The same analyzes were carried out on the wear marks.

Scanning electron microscopy (SEM) (Tescan Vega 3) was used to analyze morphological characteristics of the wear marks on the DLC-coated pistons and cylinders using $10 \mathrm{kV}$ of acceleration voltage. Chemical analyzes were performed on the surfaces using energy dispersive spectroscopy (EDS) (Oxford Instruments AZtecOne) with 10 and $5 \mathrm{kV}$ acceleration voltages. $5 \mathrm{kV}$ was used to detect the signal as close as possible from the surface. To characterize the tribolayers and the coating, Raman analysis (Renishaw inVia micro-Raman with a $514 \mathrm{~nm}$ Ar laser) was performed on the DLC and various wear marks zones. A widely adopted procedure to analyze a-C:H Raman spectra was used: the Raman spectra were obtained by firstly removing the baseline from the Raman signal, and secondly, a Gaussian fitting was used to determine $\mathrm{D}$ and $\mathrm{G}$ bands positions and intensities. From these values, the ID/IG ratio was calculated (Robertson, 2002; Sánchez-López et al., 2003; Casiraghi et al., 2005). The cross-section of a piston before tests was metallographically
TABLE 5 | Surface topographical parameters before tribological tests.

\begin{tabular}{lccc}
\hline Surface & $\mathbf{S}_{\mathbf{a}}(\boldsymbol{\mu} \mathbf{m})$ & $\mathbf{S}_{\mathbf{q}}(\boldsymbol{\mu} \mathbf{m})$ & Texture isotropy (\%) \\
\hline Cylinder & $0.102 \pm 0.018$ & $0.147 \pm 0.030$ & 2.05 \\
Coated piston & $0.029 \pm 0.006$ & $0.060 \pm 0.009$ & 4.22 \\
\hline
\end{tabular}

prepared via grinding (up to \#1200), polishing (alumina $1 \mu \mathrm{m}$ ), and etching (Nital 2\%) to evaluate the coating microstructure and measure its thickness using an optical microscope (Leica DM6).

\section{Results and Discussion}

Figure 8 shows the axonometric projection of the topography of the original cylinders and DLC-coated pistons. It is important to notice the one order of magnitude difference between the scales, which is lower for the pistons. The arrows point the sliding direction. In both cases, transversal to the sliding direction, it is possible to see grooves originated from the machining processes, whereas the surfaces of the pistons have a much smoother aspect. On the cylinder, they are parallel among one another while being crossed on the coated piston surface.

Roughness parameters of the original surfaces are presented in Table 5. As already qualitatively observed in Figure 8, Sa and Sq parameters are approximately three times higher for the cylinder. Furthermore, both surfaces are strongly anisotropic, as the low texture isotropy values demonstrate.

Figure 9 presents the typical microstructure and Raman spectrum results of the coating before tribological testing. In the coating cross-section (Figure 9A) is possible to observe the DLC film and the chromium nitride layer, which provides mechanical support to the DLC. The DLC coating has an average thickness of $1.40 \pm 0.04 \mu \mathrm{m}$ and the compound layer, $1.8 \pm 0.02 \mu \mathrm{m}$. Figure 9B shows the Raman spectrum of the DLC, which is a typical spectrum of an amorphous hydrogenated DLC (a-C:H) with an ID/ IG ratio of $0.57 \pm$ 0.01 and the $D$ and $G$ bands centered on $1,381 \pm 4 \mathrm{~cm}^{-1}$ and $1555.95 \pm 0.42 \mathrm{~cm}^{-1}$, respectively.

The typical evolution of the friction coefficient vs. sliding distance is shown in Figure 10. For the $5 \mathrm{~Hz}$ frequency and ambient air atmosphere (red curve), the friction coefficient starts at around 0.07 . It steadily increases until about $30 \mathrm{~m}$ of sliding distance, when there is a discontinuity, possibly due to a detachment of the film, which was confirmed after the test. Then, probably due to DLC debris on the contact, the friction coefficient drops again to around 0.15 (40 $\mathrm{m}$ of sliding distance) and stays steady until the end of the test.

When the testing atmosphere is changed to $\mathrm{R} 134 \mathrm{a}$ refrigerant gas, and the frequency is kept constant at $5 \mathrm{~Hz}$ (black curve), the friction coefficient behavior is drastically distinct, starting at 0.04 and maintaining this steady-state through the whole test (lubricious regime). For the frequency of $20 \mathrm{~Hz}$ and R134a atmosphere (blue curve), the typical friction coefficient does not vary much from the previous condition $(5 \mathrm{~Hz}$ and $\mathrm{R} 134 \mathrm{a}$ atmosphere), and it is steady at around 0.05 . The average friction coefficient is statistically the same for 5 and $20 \mathrm{~Hz}$ under the refrigerant gas atmosphere, as shown in Figure 5, which indicates 

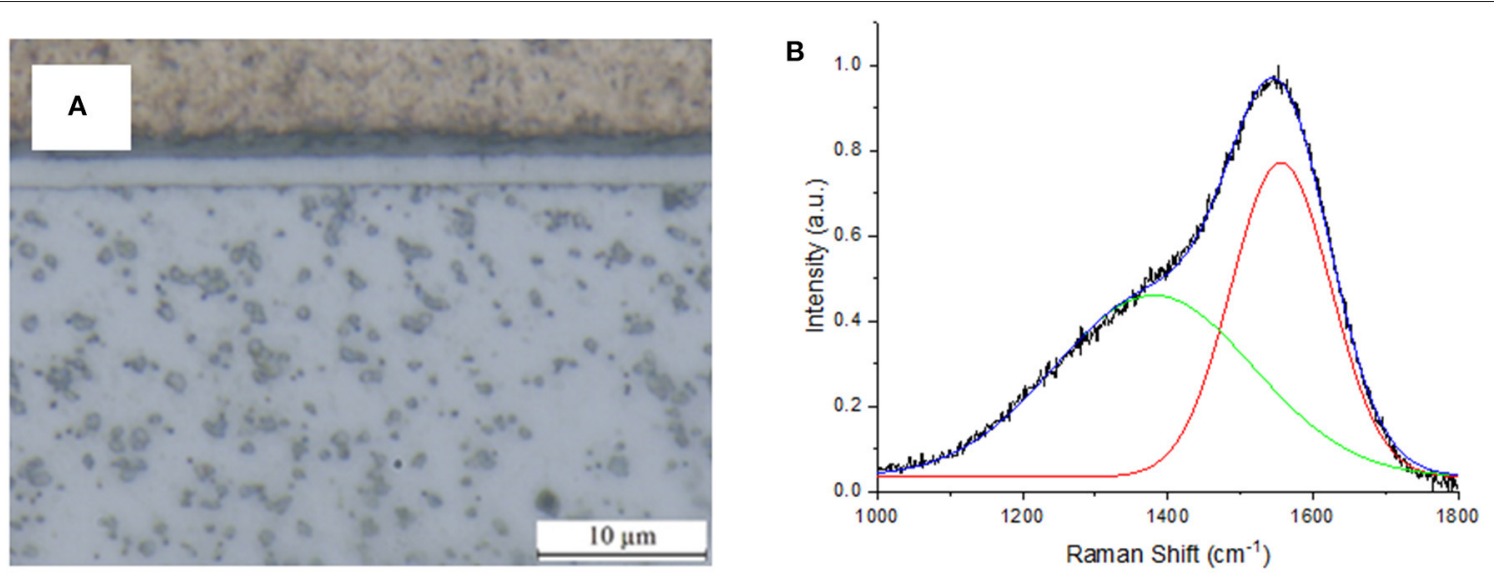

FIGURE 9 | Typical analyzes of DLC coating before tests on (A) microstructure and (B) Raman spectrum.

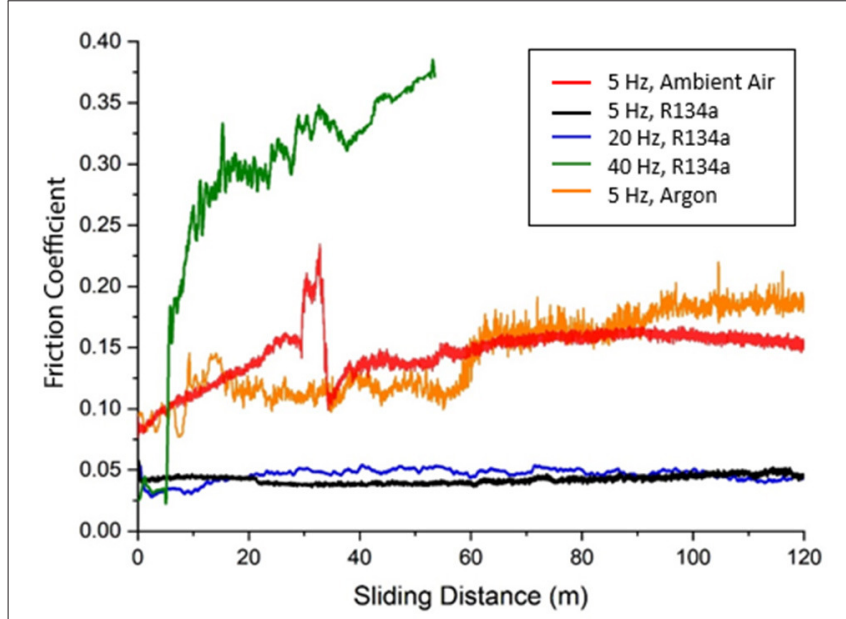

FIGURE 10 | Effect of imposed tribological parameters on friction coefficient evolution.

that similar lubricity mechanisms govern the friction under these conditions. The friction coefficient of the tests carried out at a higher frequency of $40 \mathrm{~Hz}$ (green curve) starts as low as the other tests performed under lower frequencies ( 5 and $20 \mathrm{~Hz}$ and R134a atmosphere). Still, it starts to rapidly increase in the very first meters $(\sim 2.5 \mathrm{~m})$ of sliding, reaching values as high as 0.40 . In these cases, due to the high temperatures of the emulator system, the DLC failed, and the tests had to be interrupted at $\sim 50 \mathrm{~m}$ of sliding distance.

To understand if the decrease of the friction coefficient was, indeed, associated with the atmosphere, a test $(5 \mathrm{~Hz})$ was performed under an inert argon atmosphere (orange curve). Indeed, the observed friction coefficient was higher than those obtained under the refrigerant gas atmosphere, and it has a tribological behavior similar to the one observed under ambient air.

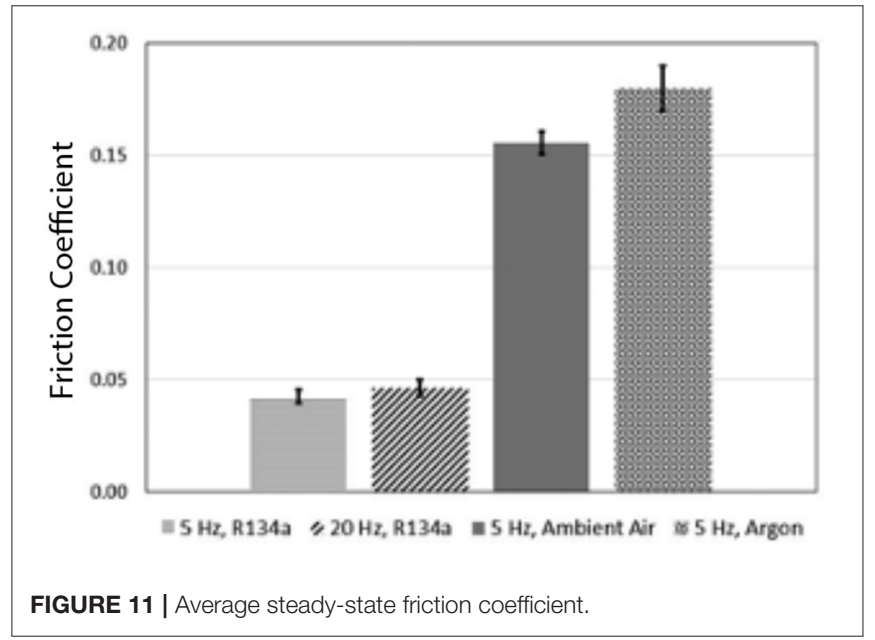

Analyzing the average friction coefficient during the steadystate for each testing condition presented in Figure 11, it is clear that the refrigerant gas atmosphere induces lower friction coefficients for 5 and $20 \mathrm{~Hz}$ frequency.

The presence of tribolayers was verified for the ambient air testing atmosphere. Additionally, significant amounts of debris were observed scattered around the contact region, as shown in Figure 12A. Tribolayers was also found on the testing performed with 5 and $20 \mathrm{~Hz}$ under the refrigerant gas atmosphere (Figure 12B). However, significantly less, and in some cases even none, debris was detected surrounding the tribolayers. Moreover, the original topographical features of the surfaces (machining grooves) are still visible, which indicates that the tribological contact does not induce high plastic deformation on the cylinder surface. No tribolayers were observed for tests under argon atmosphere or $40 \mathrm{~Hz}$ frequency with refrigerant gas.

Severe plastic deformation is observed in the burnished area of the pistons tested under ambient air atmosphere, as shown in Figure 12C. Therefore, as previously mentioned, the DLC 

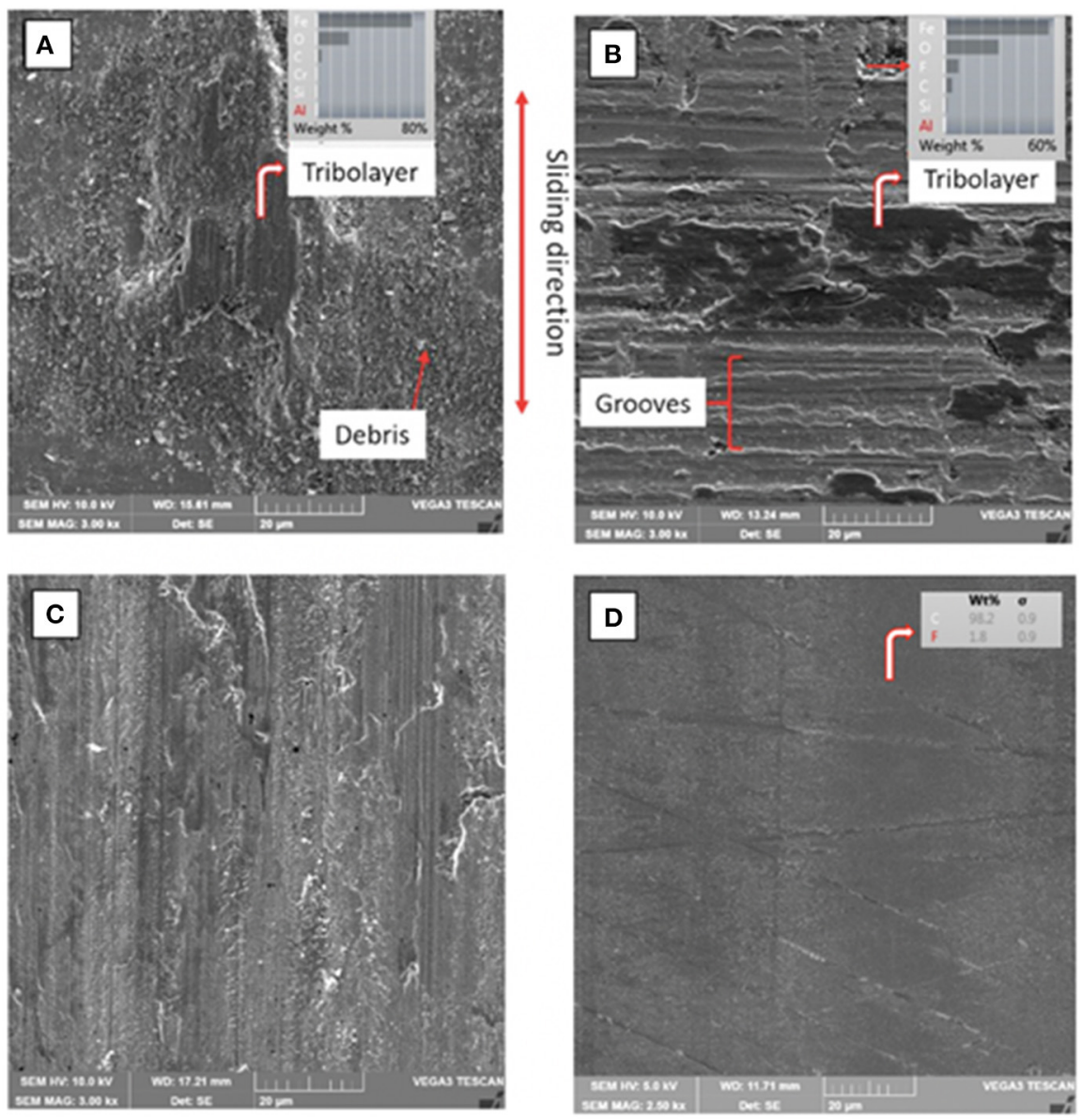

FIGURE 12 | Typical SEM images of the tested areas of the (A) cylinders under refrigerant gas. (B) Cylinders under ambient air. (C) DLC piston under ambient air. (D) DLC piston under refrigerant gas. The inserts are a summary of the analysis by EDS.

coating was removed due to the tribological action. However, the DLCs tested under R134a atmosphere (5 and $20 \mathrm{~Hz}$ ) present an integral aspect (Figure 12D).

Figure 13 illustrates typical Raman spectra of the tribolayers on the cylinders. They are similar regardless of the atmosphere (ambient air or refrigerant gas), presenting typical D and $G$ bands. Additionally, the ID/IG ratios are always greater than the unit. The $\mathrm{G}$ bands show a dislocated position to a higher Raman shift (1610.00 cm-1 instead of $1555.95 \mathrm{~cm}-1)$, as already observed by Salvaro et al. (2017).

This result indicates that the carbon presents itself as a highly disordered and high defect density graphitic structure in the tribolayers (Ferrari and Robertson, 2001; Robertson, 2002; Casiraghi et al., 2005). According to Salvaro et al. (2017), the graphitization of the uppermost layer of the DLC coating associated with DLC debris due to the contact are probably, the leading cause of disorder of the graphite-based tribolayer.

Using WLI, the tribolayers thicknesses were calculated by subtracting the average tribolayers height from the average height of their vicinities height, as demonstrated in Figure 14A. The results for the tests performed under the refrigerant gas atmosphere (5 and $20 \mathrm{~Hz}$ frequencies) are equivalent, with an

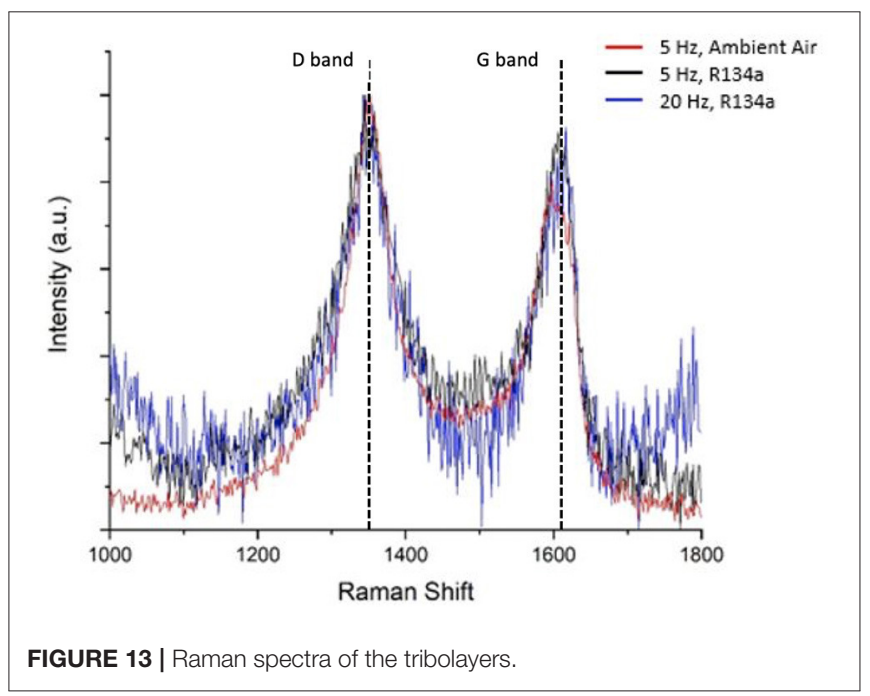

average thickness of around $800 \mathrm{~nm}$ for both cases. For the ambient air condition, the average tribolayers thickness is $1.3 \mathrm{um}$, but the standard deviation is significantly higher (Figure 14B) as 
A

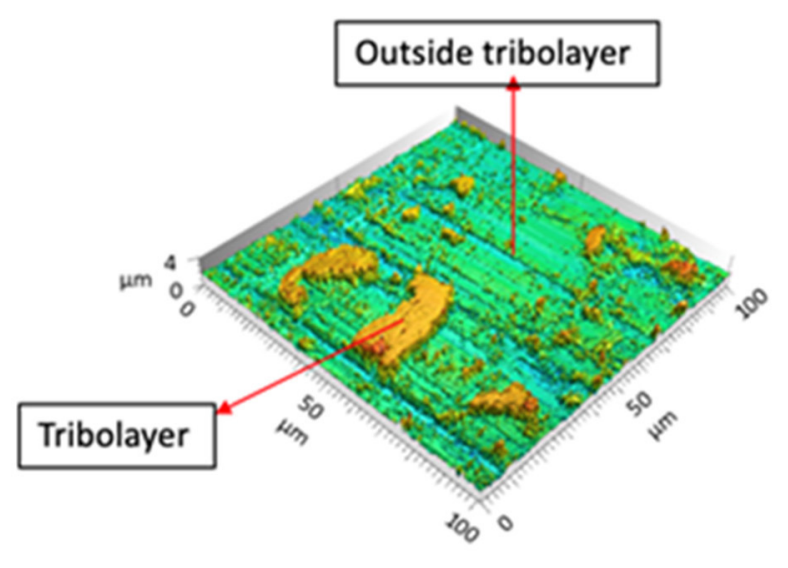

B

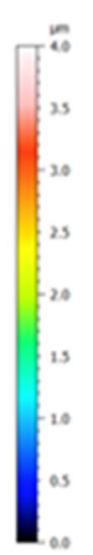

3000

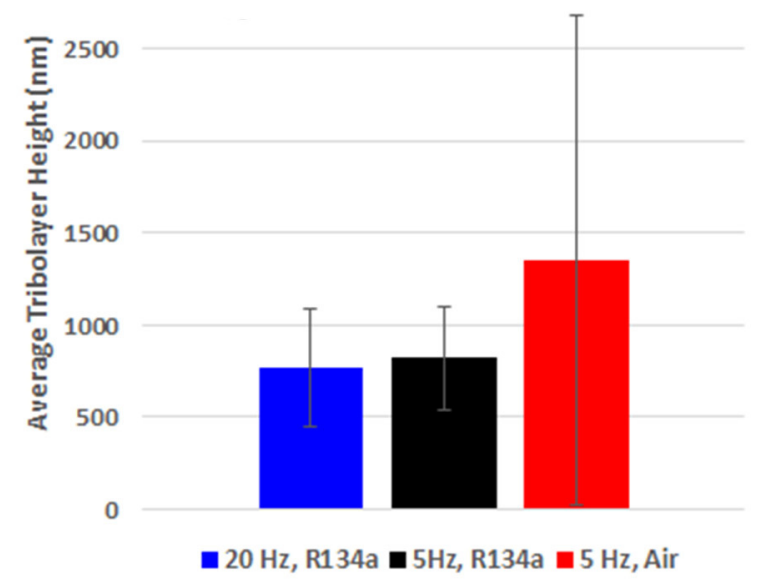

FIGURE 14 | (A) Typical tested cylinder topography with tribolayers and (B) average tribolayer height.

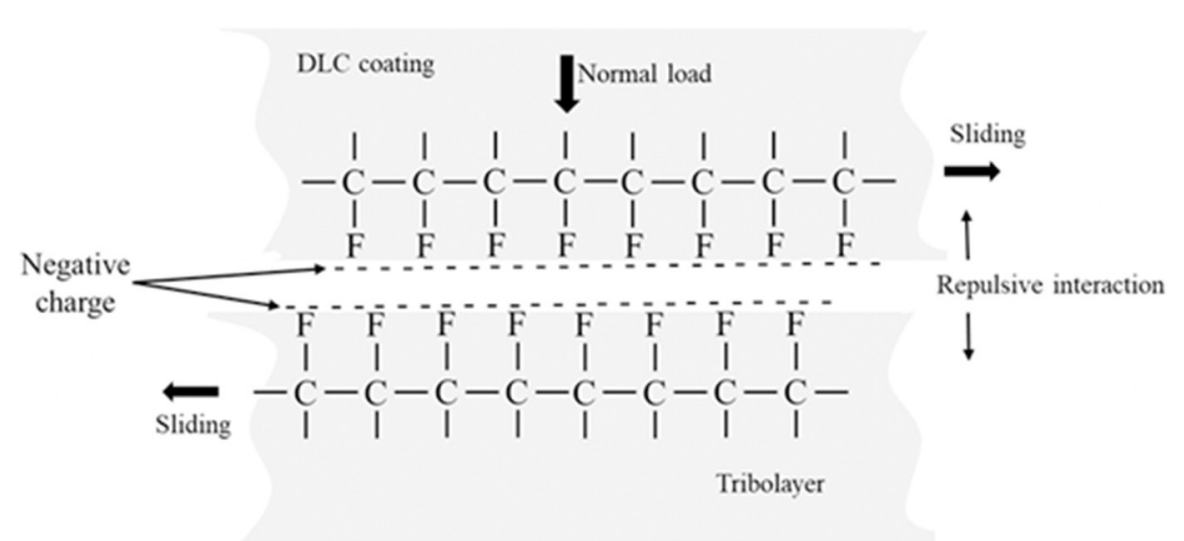

FIGURE 15 | Illustration of the fluorination effect on the repulsive interaction of carbon-based surfaces (Wang et al., 2013).

a consequence of the gradual formation of a non-continuous and non-homogeneous tribolayer presenting areas containing thinner and less uniform tribolayer whereas other areas show thicker and well-formed tribolayer as described by Barbosa et al. (2015).

Figure 12A shows the EDS analyzes of the tribolayers formed under ambient air. It indicates that they are constituted of iron, carbon, and oxygen, typical elements from cylinder/piston (substrate), coating, and atmosphere, respectively. Therefore, the tribolayers result from wear debris mixed, comminuted, oxidized, and compressed in the contact. Similar results were found on the tribolayers generated under the R134a refrigerant gas atmosphere (Figure 12B), but in this case, a systematic presence of fluorine originated from the R134a was detected. The burnished areas on the DLC piston tested under the refrigerant gas atmosphere also had detectable fluorine, but in low concentration $(\sim 1.8 \% \mathrm{wt})$, besides carbon (Figure 12D).
According to Wang et al. (2013) and Yu et al. (2003), fluorine can connect itself with carbon's dangling bonds on the surface (C-F). The tribological work wears out the cylinder and piston (DLC), thus inducing high-disorder, high-defect density graphite (graphitization). During this process, the energy available in the contact is enough to break F-C bonds in the R134a molecule, which leaves fluorine ions free to recombine with the carbon from tribolayers on the cylinder or DLC coating on the piston ( 5 and $20 \mathrm{~Hz}$ ), therefore an in situ tribofluorination phenomenon.

Wang et al. (2013) have also shown that the polar fluorinecarbon bond on the uppermost layer of the surface results in a "smoother" surface electron density distribution. Thus, repulsive interactions govern the friction coefficient between two surfaces with these features in tribological interaction, as shown in Figure 15. 
In other words, in situ tribo-graphitization and tribofluorination of carbon structures in the tribolayers and DLC coating present a positive synergy to reduce the friction coefficient of the oil-less hermetic compressor piston-cylinder tribopair.

\section{Conclusions}

In this study, a proprietary tribological emulator was used to test a piston-cylinder tribopair from an oil-less hermetic compressor. DLC coated piston against $1 / 4$ stainless steel cylinder were tested under close-to-real conditions, including the atmosphere (R134a). Additionally, tests with ambient and inert atmospheres were performed to evaluate the effect of these parameters on the tribological performance. The following conclusions were reached.

1. The friction coefficients are four times smaller when using a fluorine-rich testing atmosphere compared to the ambient atmosphere. However, in higher frequencies $(40 \mathrm{~Hz})$, the friction coefficient does not stabilize, reaching values over 0.4 , and the DLC coating fails.

2. Tribolayers found under refrigerant gas atmosphere have similar thicknesses $(\sim 800 \mathrm{~nm})$. In contrast, tribolayers formed under ambient air conditions have scattered thicknesses.

3. The friction coefficient is governed by the formation of tribolayers on the cylinders. All tribolayers found contain $\mathrm{Fe}$, $\mathrm{O}$, and $\mathrm{C}$. The carbon is present as a highly disordered and highly defects-dense graphitic structure. Under refrigerant gas atmosphere, carbon dangling bonds on the uppermost tribolayers surface and DLC coating are completed by fluorine from the refrigerant atmosphere, resulting in a repulsive interaction between the surfaces, consequently inducing low coefficients of friction $(\sim 0.04)$.

4. In situ tribo-fluorination of carbon structures in the tribolayers and DLC is feasible and represents a new, costeffective and way to control friction and wear on -less hermetic compressor piston-cylinder tribopair.

\section{CONCLUDING REMARKS}

In the present work, we overview the multidisciplinary development of a regular, lubricated, hermetic compressor which works in an on-off cycle, circular motion, singlespeed, many tribological contacts, into an innovative, linear motion, variable displacement, single tribological contact, oilless hermetic compressor presenting high versatility in terms of refrigerator design, sustainability and improved efficiency. The original approach encompassed the development of new surface engineering procedures applying purpose-oriented phases to soft substrates. Different types of multi-layers, their thickness, substrate material, processing routes, etc., have been studied

\section{REFERENCES}

Agarwal, K., Shivpuri, R., Vincent, J., Rolinski, E., and Sharp, G. (2013). DC pulsed plasma deposition of nanocomposite coatings for improved tribology of gray cast iron stamping dies. J. Mater. and optimized in this context. The results clearly show that the tribological behavior of carbon derived coatings is strongly influenced by the surrounding atmosphere. Si-rich hydrogenated DLC (a:C-H) presented enhanced tribological properties when tested under fluorine-rich atmospheres demonstrating the feasibility of the in situ tribo-fluorination of carbon structures, which represents a new, cost-effective and efficient way to control friction and wear on oil-free hermetic compressor pistoncylinder tribopair.

\section{DATA AVAILABILITY STATEMENT}

The original contributions presented in the study are included in the article/supplementary material, further inquiries can be directed to the corresponding author/s.

\section{AUTHOR CONTRIBUTIONS}

GB was the main investigator regarding in situ fluorination, supervised the obtainment of the samples, supervised all the experiments, described and co-analyzed the results, and wrote the first short draft of the paper. DS helped supervise the research and contributed to analyzing the results, particularly those related to tribo-tests, and helped write the first short draft of the paper. $\mathrm{CB}$ was responsible for managing the various phases of the project, helped supervise the research, and contributed to analyzing the results. RB helped design the whole project, actively participated in the management, fundraising, and analysis of the results. AK helped design the whole project, its management, and supervision, to analyze the results and financing of the different stages. JM designed the entire project, particularly the tribological aspects, supervised the research, helped to analyze the results, and had a major role in the conception and writing of the final manuscript. All authors contributed to the article and approved the submitted version.

\section{ACKNOWLEDGMENTS}

The authors acknowledge the agencies for funding this research: Fulbright Commission (USA), CNPq, FAPEMIG, BNDES, CAPES-PROEX (Brazil) as well as Nidec Global Appliance/Embraco. Special thanks are due to our co-authors: M. Sc. M.V. Barbosa, UFSC; Dr. T. Bendo, UFSC; Prof. H.L. Costa, UFU; Dr. N. Demas, Argone National Laboratory; Dr. R.O. Giacomelli, UFSC; Dr. G. Hammes, UFSC; M. Sc. E.R. Hulse, Nidec Global Appliance/Embraco; M. Sc. T.S. Lamim, UFSC; Dr. L.O.C. Lara, UFES; Prof. A. Polycarpou, Texas A\&M; Dr. M.B dos Santos, UFU; Dr. P.H.T. Shioga, UFSC; M. Sc. M. Silverio, Nidec Global Appliance/Embraco; M. Sc. P.B Soprano, Nidec Global Appliance/Embraco. 
Barbosa, M. V. (2014). Desenvolvimento de Metodologia de Caracterização Fisico-Química de Tribocamada. Ms.C Dissertation, Universidade Federal de Santa Catarina.

Barbosa, M. V., Hammes, G., Binder, C., Klein, A. N., and de Mello, J. D. B. (2015). Physicochemical characterisation of tribolayers by micro-Raman and GDOES analyses. Tribol. Int. 81, 223-230. doi: 10.1016/j.triboint.2014.09.008

Belin, M. (1993). Triboscopy: a new quantitative tool for microtribology. Wear 168, 7-12. doi: 10.1016/0043-1648(93)90190-W

Boeng, J., and Melo, C. (2014). Mapping the energy consumption of household refrigerators by varying the refrigerant charge and the expansion restriction. Int. J. Refrigeration 37-44. doi: 10.1016/j.ijrefrig.2013.06.005

Brookes, C. A., and Brookes, E. J. (1991). Diamond in perspective: a review of mechanical properties of natural diamond. Diamond Relat. Mater. 1, 13-17. doi: 10.1016/0925-9635(91)90006-V

Calm, J. M. (2000). Toxicity Data To Determine Refrigerant Concentration Limits, Vol. 110. ARTI Report Doe/Ce/23810-110. Arlington, VA: Air-Conditioning and Refrigeration Technology Institute, 1-508.

Cannaday, M. L., and Polycarpou, A. A. (2005). Tribology of unfilled and filled polymeric surfaces in refrigerant environment for compressor applications. Tribol. Lett. 19, 249-262. doi: 10.1007/s11249-005-7441-9

Casiraghi, C., Piazza, F., Ferrari, A. C., Grambole, D., and Robertson, J. (2005). Bonding in hydrogenated diamond-like carbon by Raman spectroscopy. Diam. Relat. Mater. 14, 1098-1102. doi: 10.1016/j.diamond.2004.10.030

Cheng, H. L., Mei, B. J., Liu, Y. N., Huang, Y. H., and Yuan, X. D. (2011). A novel household refrigerator with shape-stabilized PCM (Phase Change Material) heat storage condensers: An experimental investigation. Energy 36, 5797-5804. doi: 10.1016/j.energy.2011.08.050

Cho, C. W., Hong, B., and Lee, Y. Z. (2005). Wear life evaluation of diamond-like carbon films deposited by microwave plasma-enhanced CVD and Rf plasmaenhanced CVD method. Wear 259, 789-794. doi: 10.1016/j.wear.2005.02.007

Corbella, C., Vives, M., Oncins, G., Canal, C., Andújar, J. L., and Bertran, E. (2004). Characterization of DLC films obtained at room temperature by pulsed-dc PECVD. Diam. Relat. Mater. 13, 149-1499. doi: 10.1016/j.diamond.2003.10.079

Dalibon, E. L., Charadia, R., Cabo, A., and Trava-Airoldi, V. J., Brühl, S. P. (2013). Evaluation of the mechanical behaviour of a DLC film on plasma nitrided AISI 420 with different surface finishing. Surf. Coat. Technol. 235, 735-740. doi: 10.1016/j.surfcoat.2013.08.059

de Mello, J. D. B. (1983). Structure metallurgique et caracterization de l'abrasion des fontes blanches au chrome, Doctorate Thesis, Institut National Polytechique de Grenoble.

de Mello, J. D. B., Binder, C., Binder, R., and Klein, A. N. (2010). Effect of nature of nitride phases on microabrasion of plasma nitrided sintered iron. Tribol. Mater. Surf. Interfaces 4,191-196. doi: 10.1179/1751584X10Y.0000000001

de Mello, J. D. B., and Binder, R. (2006). A methodology to determine surface durability in multifunctional coatings applied to soft substrates. Tribol. Int. 39, 769-773. doi: 10.1016/j.triboint.2005.07.015

de Mello, J. D. B., Binder, R., Demas, N. G., and Polycarpou, A. A. (2009). Effect of the actual environment present in hermetic compressors on the tribological behaviour of a Si-rich multifunctional DLC coating. Wear 267, 907-915. doi: 10.1016/j.wear.2008.12.070

Donnet, C., Belin, M., Aug,é, J. C., Martin, J. M., Grill, A., and Patel, V. (1994). Tribochemistry of diamond-like carbon coatings in various environments. Surf. Coatings Technol. 68-69, 626-631. doi: 10.1016/0257-8972(94)90228-3

Donnet, C., and Erdemir, A. (2004). Historical developments and new trends in tribological and solid lubricant coatings. Surface Coatings Technol. 180-181, 76-84. doi: 10.1016/j.surfcoat.2003.10.022

Donnet, C., and Erdemir, A. (2008). Tribology of Diamond-Like Carbon Films: Fundamentals and Applications. New York, NY: Springer. doi: 10.1007/978-0-387-49891-1

Donnet, C., and Grill, A. (1997). Friction control of diamond-like carbon coatings. Surf. Coat. Technol. 94/95, 456-462. doi: 10.1016/S0257-8972(97)00275-2

dos Santos, M. B., Costa, H. L., and De Mello, J. D. B. (2015). Potentiality of triboscopy to monitor friction and wear. Wear 332-333, 1134-1144. doi: 10.1016/j.wear.2014.10.017

Ebrahimi, M., Mahboubi, F., and Naimi-Jamal, M. R. (2015). Wear behavior of DLC film on plasma nitrocarburized AISI 4140 steel by pulsed DC PACVD: effect of nitrocarburizing temperature. Diam. Relat. Mater. 52, 32-37. doi: 10.1016/j.diamond.2014.12.004
Embraco (2019). Embraco develops complete and innovative refrigeration solutions for a better quality of life. Available online at: https://www.embraco. com/en/embraco-develops-complete-and-innovative-refrigeration-solutionsfor-a-better-quality-of-life/.

Erdemir, A. (2001). Modern Tribology Handbook II. CRC Press, 787-825.

Erdemir, A., Eryilmaz, O. L., and Fenske, G. (2000a). Synthesis of diamond like carbon films with superlow friction and wear properties. J. Vacuum Sci. Technol. 18, 1987-1992. doi: 10.1116/1.582459

Erdemir, A., Eryilmaz, O. L., Nilufer, B., and Fenske, G. R. (2000b). Effect of source gas chemistry on tribological performance of diamond-like carbon films. Diamond Related Mater. 9, 632-637. doi: 10.1016/S0925-9635(99)00361-1

Feng, Z., and Field, J. E. (1991). Friction of diamond on diamond and chemical vapour deposition diamond coatings. Surf. Coat. Technol. 47, 631-645. doi: 10.1016/0257-8972(91)90335-T

Ferrari, A. C., and Robertson, J. (2001). Resonant Raman spectroscopy of disordered, amorphous, and diamondlike carbon, Phys. Rev. B 64:075414. doi: 10.1103/PhysRevB.64.075414

Field, J. E. (2012). The mechanical and strength properties of diamond. Rep. Prog. Phys. 75:126505. doi: 10.1088/0034-4885/75/12/126505

Franks, J., Enke, K., and Richardt, A. (1990). Diamond-like carbon - properties and applications. Met. Mater. 11, 695-700.

Giacomelli, R. O., Salvaro, D. B., Bendo, T., Binder, C., Klein, A. N., and de Mello, J. D. B. (2017). Topography evolution and friction coefficient of grey and nodular cast irons with duplex plasma nitrided +DLC coating. Surf. Coatings Technol. 314, 18-27. doi: 10.1016/j.surfcoat.2016.09.035

Grill, A. (1997). Tribology of diamondlike carbon and related materials: an updated review. Surf. Coat. Technol. 94-95, 507-513. doi: 10.1016/S0257-8972(97)00458-1

Holmberg, K., and Erdemir, A. (2017). Influence of tribology on global energy consumption, costs and emissions. Friction 5, 263-284. doi: 10.1007/s40544-017-0183-5

Holmberg, K., Matthews, A., and Ronkainen, H. (1998). Coatings tribologycontact mechanisms and surface design. Tribol. Int, 31, 107-120. doi: 10.1016/S0301-679X(98)00013-9

Holmberg, K., and Matthews, A. (1994). Coatings Tribology-Properties, Techniques and Applications in Surface Engineering. Volume 28, 1st Edition. Oxford: Coatings Tribology, Elsevier Science.

International Institute of Refrigeration (2015). 29th Informatory Note on refrigeration technologies: The role of refrigeration in the global economy. Paris: International Institute of Refrigeration, 16.

Jeong, B. Y., and Kim, M. H. (2001). Effects of pulse frequency and temperature on the nitride layer and surface characteristics of plasma nitrided stainless steel. Surf. Coat. Technol. 137, 249-254. doi: 10.1016/S0257-8972(00)01095-1

Jost, H. P. (1990). Tribology - origin and future. Wear 136, 1-17. doi: 10.1016/0043-1648(90)90068-L

Karakan, M., Alsaran, A., and elik, A. (2002). Effects of various gas mixtures on plasma nitriding behavior of AISI 5140 steel. Mater. Charact. 49, 241-246. doi: 10.1016/S1044-5803(03)00010-X

Karamiş, M. B., and Yildizli, K. (2010). Surface modification of nodular cast iron: a comparative study on graphite elimination. Mater. Sci. Eng. A 527, 5225-5229. doi: 10.1016/j.msea.2010.04.067

Lamim, T. S., Salvaro, D., Giacomelli, R. O., Binder, R.,C; Klein, A. N, and de Mello, J. D. B. (2019). "The effect of using hollow cathode on the tribological behavior of plasma nitrided layers," in Progress in Mechanisms and Machine Science. 1ed, (Kracow, Pl: Springer International Publishing), 3893-3902. doi: 10.1007/978-3-030-20131-9_386

Lancaster, J. K. (1984). "Solid lubricants," in CRC Handbook of Lubrication, Theory and Practice of Tribology, vol. II, Theory and Design, ed E.R. Booser (Boca Raton, FL: CRC Press), 269-290, 1984 doi: 10.1201/9781420050448.ch16

Lansdown, A. R. (1999). Molybdenum Disulphide Lubrication Tribology Series, ed D. Dowson. Amsterdam: Elsevier Science, 35.

Lara, L. O. C., Costa, H. L., and De Mello, J. D. B. (2015). Influence of layer thickness on sliding wear of multifunctional tribological coatings. Ind. Lubr. Tribol. 460, 460-467. doi: 10.1108/ILT-01-2015-0010

Lara, L. O. C., and De Mello, J. D. B. (2012). Influence of layer thickness on hardness and scratch resistance of Si-DLC/CrN coatings. Tribol. Mater. Surf. Interfaces 6, 168-173. doi: 10.1179/1751584X12Y.00000 00019 
Lara, L. O. C., and De Mello, J. D. B. (2015). Quantitative measurement of the interface adhesion of a multifunctional coating. Lett. Appl. NanoBioSci. 4, 301-305.

Liu, Y., Erdemir, A., and Meletis, E. I. (1996). An investigation of the relationship between graphitization and frictional behavior of DLC coatings. Surf. Coatings Technol. 86-87, 564-568. doi: 10.1016/S0257-8972(96)03 057-5

Liu, Y., and Meletis, E. I. (1997). Evidence of graphitization of diamondlike carbon films during sliding wear. J. Mater. Sci. 32, 3491-3495. doi: 10.1023/A:1018641304944

Maliska, A. M. (1995). Influência de elementos de liga e do oxigênio no processo de nitretação por plasma em aços sinterizados. Universidade Federal de Santa Catarina, Florianópolis, Doctorate Thesis.

Marciano, F. R., Almeida, E. C., Lima-Oliveira, D., and Corat, E.,J., TravaAiroldi, V. J. (2010). Improvement of DLC electrochemical corrosion resistance by addiction of fluorine. Diam. Relat. Mater. 19:537-540 doi: 10.1016/j.diamond.2009.12.015

Masuko, M., Kudo, T., and Suzuki, A. (2013). Effect of Surface Roughening of Substrate Steel on the Improvement of Delamination Strength and Tribological Behavior of Hydrogenated Amorphous Carbon Coating Under Lubricated Conditions, Tribology Letters, 51, 181-190. doi: 10.1007/s11249-0130106-1

Maurizi, M., Tomanik, E., and Rejowski, E. (2014). "DLC coated liners for fuel savings," in VDI-Fachtagung Mit Fachstellung Zyllinderlaufbahn Kolben, Pleuel, VDI (Baden-Baden)

Miyoshi, K. (1995). Structures and mechanical properties of natural and synthetic diamonds. Diamond Films Technol. 8, 153-172.

Oguri, K., and Arai, T. (1991). Tribological properties and characterization of diamond-like carbon coatings with silicon prepared by plasmaassisted chemical vapour deposition. Surf. Coat. Technol. 47, 710-721. doi: 10.1016/0257-8972(91)90344-V

Ohana, T., Nakamura, T., Suzuki, M., Tanaka, A., and Koga, Y. (2004a). Tribological properties and characterization of DLC films deposited by pulsed bias CVD. Diamond Relat. Mater. 4-8, 1500-1504. doi: 10.1016/j.diamond.2003.11.019

Ohana, T., Suzuki, M., Nakamura, T., Tanaka, A., and Koga, Y. (2004b). Tribological properties of DLC films deposited on steel substrate with various surface roughness. Diamond Relat. Mater. 13, 2211-2215. doi: 10.1016/j.diamond.2004. 06.037

Pergande, S. R., Polycarpou, A. A., and Conry, T. F. (2004). Nanomechanical properties of aluminum 390-T6 rough surfaces undergoing tribological testing, J. Tribol. 126, 573-582. doi: 10.1115/1.1698949

Pinedo, C. E., and Monteiro, W. A. (2001). Surface hardening by plasma nitriding on high chromium alloy steel. J. Mater. Sci. Letters 20, 157-163. doi: 10.1023/A:1006723225515

Podgornik, B., Sedlaček, M., and ViŽintin, J. (2008). Compatibility of DLC coatings with formulated oils. Tribol. Int. 41, 564-570. doi: 10.1016/j.triboint.2007.12.004

Rechberger, J., Brunner, P., and Dubach, R. (1993). High performance cutting tools with a solid lubricant physically vapour- deposited coating. Surf. Coat. Technol. 62 393-398. doi: 10.1016/0257-8972(93) 90273-Q

Robertson, J. (2002). Diamond-like amorphous carbon. Mater. Sci. Eng. R Reports 37, 129-281. doi: 10.1016/S0927-796X(02)00005-0

Rolinski, E., Konieczny, A., and Sharp, G. (2007). Influence of nitriding mechanisms on surface roughness of plasma and gas nitrited/nitrocarburized gray cast iron. Heat Treat Prog. 7, 39-46.

Rolinski, E., Konieczny, A., and Sharp, G. (2009). Nature of surface changes in stamping tools of gray and ductile cast iron during gas and plasma nitrocarburizing. J. Mater. Eng. Perform. 18, 1052-1059. doi: 10.1007/s11665-009-9352-7

Salvaro, D. B., Giacomelli, R. O., Binder, R., Binder, C., Klein, A. N., and de Mello, J. D. B. (2017). Assessment of a multifunctional tribological coating (nitride+DLC) deposited on grey cast iron in a mixed lubrication regime. Wear 376-377, 803-812. doi: 10.1016/j.wear.2017.01.079

Salvaro, D. B., Silvério, M., Binder, C., Giacomelli, R.O., Klein, A. N., de Mello, J. D. B. (2016). Genesis and stability of tribolayers in solid lubrication: case of pair DLC-stainless steel. J. Mater. Res. Technol. 5, 136-143. doi: 10.1016/j.jmrt.2015.10.008

Sánchez-López, J. C., Erdemir, A., Donnet, C., and Rojas, T. C. (2003). Friction-induced structural transformations of a diamondlike carbon coatings under various atmospheres. Surf. Coatings Technol. 163-164, 444-450. doi: 10.1016/S0257-8972(02)00641-2

Shioga, P. H. T., Binder, C., Hammes, G., Klein, A. N., and De Mello, J. D. B. (2016). Effects of different plasma nitrided layers on the tribological performance of DLC coatings. Mater. Res. 19, 1180-1188. doi: 10.1590/1980-5373-MR-2015-0455

Silverio, M., Binder, R., Hulse, E. R., and de Mello, J. D. B. (2016). "Effect of refrigerant gases (HFC134a and R600a) on the tribological behaviour of a multifunctional coating," in Proceedings of the $23^{\text {rd }}$ International Compressor Engineering Conference at Purdue, Purdue University, Paper. Available online at: https://docs.lib.purdue.edu/icec/2413

Silverio, M., de Mello, J. D. B., and Binder, R. (2010). "Effect of refrigerant gases on the tribological behavior of a CrN-SiDLC multifunctional coating applied to soft substrate," in Proceedings of the First International Brazilian Conference on Tribology - TriboBr-2010, (Rio de Janeiro)

Singh, G. P., Alphons, J., Barhai, P. K., Rayjad, P. A., Raoleb, P. M., Mukherjee, S. (2006). Effect of surface roughness on the properties of the layer formed on AISI 304 stainless steel after plasma nitriding. Surf. Coat. Technol. 200, 5807-5811. doi: 10.1016/j.surfcoat.2005.08.149

Solzak, T. A., and Polycarpou, A. A. (2006). Tribology of WC/C coatings for use in oil-less piston type compressors. Surf. Coat. Tech. 201, 4260-4265. doi: 10.1016/j.surfcoat.2006.08.087

Soprano, P. B., Salvaro, D. B., Giacomelli, R. O., Binder, C., Klein, A. N., and de Mello, J. D. B. (2018). Effect of soft substrate topography on tribological behavior of multifunctional DLC coatings. J. Braz. Soc. Mech. Sci. Eng. 40:371. doi: 10.1007/s40430-018-1290-6

Spalvins, T. (1983). Tribological and microstructural characteristics of ion-nitrided steels. Thin Solid Films 108, 157-163. doi: 10.1016/0040-6090(83)90500-X

Sung, J. C., Kan, M. C., and Sung, M. (2009). Fluorinated DLC for tribological applications. Int. J. Refract. Met. Hard Mater. 27, 421-426. doi: 10.1016/j.ijrmhm,.2008.11.008

Trojan, K., Grischke, M., and Dimigen, H. (1994). Network modification of DLC coatings to adjust a defined surface energy. Phys. Status Solidi. 145, 575-585. doi: $10.1002 /$ pssa.2211450242

U.S. Energy Information Administration (2015). Residential Energy Consumption Survey. Available online at: https://www.eia.gov/todayinenergy/detail.php?id= 37813

VDI (1992). VDI 3198:1992-08, Beschichten von Werkzeugen der Kaltmassivumformung; CVD- und PVD-Verfahren.

Vercammen, K., Van Acker, K., Vanhulsel, A., Barriga, J., Arnsek, A., Kalin, M., et al. (2004). Tribological behaviour of DLC coatings in combination with biodegradable lubricants. Tribol. Int. 37,983-989. doi: 10.1016/j.triboint.2004.07.016

Voevodin, A. A., O’Neill, J. P., and Zabinski, J. S. (1999). Nanocomposite tribological coatings for aerospace applications. Surf. Coat. Technol. 116-119, 36-45. doi: 10.1016/S0257-8972(99)00228-5

Wang, J., Wang, F., Li, J., Sun, Q., Yuan, P., and Jia, Y. (2013). Comparative study of friction properties for hydrogen- and fluorine-modified diamond surfaces: a first-principles investigation. Surf. Sci. 608, 74-79. doi: 10.1016/j.susc.2012.09.016

Wong, V. W., and Tung, S. C. (2016). Overview of automotive engine friction and reduction trends-Effects of surface, material, and lubricant-additive technologies. Friction 4, 1-28. doi: 10.1007/s40544-016-0107-9

Yoon, H., Sheiretov, T., and Cusano, C. (1998). Tribological evaluation of some aluminum-based materials in lubricant/ refrigerant mixtures. Wear 218, 54-65. doi: 10.1016/S0043-1648(98)00195-1

Yu, G. Q., Tay, B. K., Sun, Z., and Pan, L. K. (2003). Properties of fluorinated amorphous diamond such as carbon films by PECVD. Appl. Surf. Sci. 219, 228-237. doi: 10.1016/S0169-4332(03)00644-5

Zenker, R., Buchwalder a., Rüthrich, K., Griesbach, W., and Nagel, K. (2013). First results of a new duplex surface treatment for cast iron: Electron beam remelting and plasma nitriding. Surf. Coatings Technol. 236, 58-62. doi: 10.1016/j.surfcoat.2013. 06.118 
Zhu, D., Nanbu, T., Ren, N., Yasuda, Y., and Wang, Q. J. (2010). Model-based virtual surface texturing for concentrated conformal-contact lubrication. Proc. Inst. Mech. Eng. J. Eng. Tribol. 224, 685-696. doi: 10.1243/13506501JET739

Conflict of Interest: The authors declare that the research was conducted in the absence of any commercial or financial relationships that could be construed as a potential conflict of interest.
Copyright (c) 2021 Borges, Salvaro, Binder, Binder, Klein and de Mello. This is an open-access article distributed under the terms of the Creative Commons Attribution License (CC BY). The use, distribution or reproduction in other forums is permitted, provided the original author(s) and the copyright owner $(s)$ are credited and that the original publication in this journal is cited, in accordance with accepted academic practice. No use, distribution or reproduction is permitted which does not comply with these terms. 